\title{
Identifying the Esthetically Optimal AP Position of Maxillary Incisors in Caucasian Females
}

\author{
MacKenzie Boyles-Horan
}

Follow this and additional works at: https://researchrepository.wvu.edu/etd

\section{Recommended Citation}

Boyles-Horan, MacKenzie, "Identifying the Esthetically Optimal AP Position of Maxillary Incisors in Caucasian Females" (2018). Graduate Theses, Dissertations, and Problem Reports. 5248.

https://researchrepository.wvu.edu/etd/5248

This Thesis is protected by copyright and/or related rights. It has been brought to you by the The Research Repository @ WVU with permission from the rights-holder(s). You are free to use this Thesis in any way that is permitted by the copyright and related rights legislation that applies to your use. For other uses you must obtain permission from the rights-holder(s) directly, unless additional rights are indicated by a Creative Commons license in the record and/ or on the work itself. This Thesis has been accepted for inclusion in WVU Graduate Theses, Dissertations, and Problem Reports collection by an authorized administrator of The Research Repository @ WVU. For more information, please contact researchrepository@mail.wvu.edu. 


\title{
IDENTIFYING THE ESTHETICALLY OPTIMAL AP POSITION OF MAXILLARY INCISORS IN CAUCASIAN FEMALES
}

\author{
MacKenzie Boyles-Horan, D.D.S.
}

\author{
Thesis submitted \\ to the School of Dentistry \\ at West Virginia University \\ in partial fulfillment of the requirements for the degree of
}

\section{Master of Science in \\ Orthodontics}

\author{
Peter Ngan, D.M.D. \\ Chris Martin, D.D.S., M.S. \\ Bryan Weaver, D.D.S, M.D. \\ Department of Orthodontics \\ Morgantown, West Virginia \\ 2018
}

Keywords: AP incisor position, profile, facial esthetics, VAS

Copyright 2018 MacKenzie Boyles-Horan, D.D.S. 


\title{
ABSTRACT \\ IDENTIFYING THE ESTHETICALLY OPTIMAL AP POSTION OF MAXILLARY INCISORS IN CAUCASIAN FEMALES
}

\author{
MacKenzie Boyles-Horan, D.D.S.
}

Background and Objectives: The majority of orthodontists routinely evaluate the amount of maxillary incisor display from a frontal perspective, however they do not regularly evaluate a patient's smiling profile with the teeth visible when diagnosing and treatment planning. This study uses the facial plane Glabella Vertical, a vertical line tangent to the subject's soft glabella, to classify the maxilla's AP position. The purpose of this study is to determine if there is a difference in perceived attractiveness between smiling and repose facial profiles and to identify if there is an esthetically optimal AP position of the maxillary incisors in Caucasian females.

Experimental Design and Methods: A sample of 30 young adult Caucasian females were positioned in adjusted natural head position and a repose profile photograph and a smiling profile photograph were taken with a millimeter ruler aligned with the subject's midsagittal plane. The photographs were uploaded to Microsoft PowerPoint ${ }^{\mathrm{TM}}$ and the distance from the subject's Glabella Vertical plane and FA point of the maxillary incisor was measured. Six male and 6 female orthodontic faculty/residents and 10 male and 10 female non-orthodontic professionals rated the facial attractiveness of the subjects using a visual analog scale. The data was analyzed using Tukey's test for multiple comparisons, ANOVA, and chi-square analysis.

Results: There was a statistically significant $(\mathrm{p}<0.05)$ difference in perceived attractiveness of repose and smiling profiles in half of the photographed subjects. The subjects with maxillary incisors that lie on Glabella Vertical were rated by orthodontists statistically significantly $(\mathrm{p}<0.05)$ more attractive than subjects with maxillary incisors postioned anterior or posterior to Glabella Vertical. Subjects with incisors that lie on Glabella Vertical or posterior to Glabella Vertical were rated statistically significantly $(\mathrm{p}<0.05)$ more attractive by non-orthodontists than subjects with maxillary incisors positioned anterior to Glabella Vertical.

Conclusions: In some Caucasian females there is a significant difference in perceived attractiveness of repose and smiling profiles. Orthodontists rate maxillary incisors that lie on Glabella Vertical significantly more attractive than maxillary incisors that lie anterior or posterior to Glabella Vertical. Non-orthodontists rate maxillary incisors that lie on Glabella Vertical or lie posterior to Glabella Vertical more attractive than maxillary incisors that are positioned anterior to Glabella Vertical. Non-orthodontists appear to be more tolerant of retruded maxillary incisors from a lateral smiling perspective in Caucasian females. 


\section{DEDICATION}

To my husband, Sean, I am so glad I get to spend my life with my best friend. Thank you for supporting me over the past three years. Going through residency together wasn't always easy, but at least we had each other. I can't wait to see what the future has in store for us!

To my parents, Mom and Dad, thank you for always being there for me and supporting me since forever. I truly look up to both of you and you have inspired me to pursue this profession. I love you both and am forever grateful for all you have done for my sister and me.

To my little sister, Catherine, you are such a strong and talented young woman and I am so proud of all that you are accomplishing. Thank you being there to talk when I had a bad day, you always made me feel better. I love you so much! 


\begin{abstract}
AKNOWLEDGEMENTS
I would like to bring attention to all the help and support I have been given during this research project and throughout my residency. I would not have been able to complete this program or thesis without the assistance of numerous people. Thank you for being there when I needed someone to lean on and ask for advice. It has not gone unnoticed.
\end{abstract}

Dr. Chris Martin thanks for serving as my thesis advisor. Thank you for being there to help me out whenever I needed! You have always given me great advice in the clinic and when completing this project. Thanks for all that you have taught me!

Dr. Peter Ngan, for serving on my thesis committee and helping me think of innovative solutions for issues throughout the project. Your passion for research is something that I truly admire. Thank you!

Dr. Bryan Weaver, thank you very much for being a part of my thesis committee and taking time out of your busy schedule to be a part of this process.

Dr. Timothy Tremont, thank you for all the guidance you have given me with this project. Throughout the program you have given me an advanced background in orthodontic diagnosis. You were the one who opened my eyes to this topic and for that I am extremely grateful.

Jun Xiang, I am so grateful for all the time and hard work you put into helping me with the statistical analysis. I truly could not have completed this research without you!

Dr. Tyler Crowe and Dr. Amer Shammaa, thank you for being there to support me over the past three years. I know you did not always understand my emotional responses, but you were always there to pick me up! I will miss you both.

Niki, Carl, Ghaddy, Mohamad, Sarah, and Joanna, my fellow residents, thank you for making this program fun! I wish you all the best with the rest of your residency and your careers. 


\section{TABLE OF CONTENTS}



DEDICATION_.................................................................................................................................. iii

ACKNOWLEDGEMENTS ........................................................................................................ iv

TABLE OF CONTENTS ..................................................................................................v

LISTS OF FIGURES .................................................................................................................... viii

LISTS OF TABLES........................................................................................... ix

CHAPTER 1: INTRODUCTION.........................................................................................1



STATEMENT OF THE PROBLEM ………………….................................

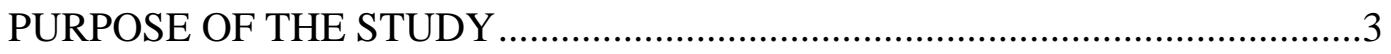

NULL HYPOTHESIS .............................................................................









CHAPTER 2: REVIEW OF THE LITERATURE.............................................................4

FACIAL ESTHETICS ……………………………………………………4

CONVENTIONAL SOFT TISSUE ANALYSIS …………………….................6

SKELETAL DIAGNOSIS USING SOFT TISSUE …………….........................

SIX ELEMENTS ORTHODONTIC PHILOSOHPY ………………………......

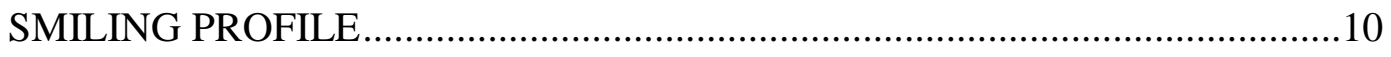

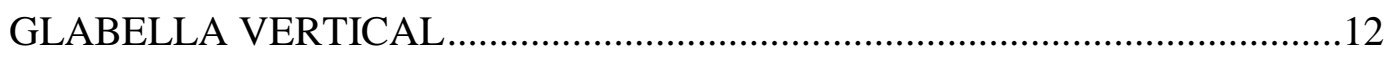

SURGICAL TREATMENT PLANNING OF MAXILLA .....................................13

NATURAL HEAD POSTURE....................................................................14 


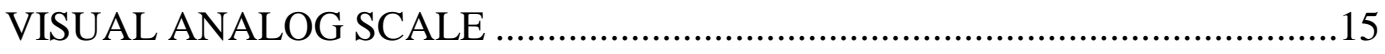

EXTRACTION VERSUS NON-EXTRACTION ………….................................15

VARIABILITIES IN RATED ATTRACTIVENESS .........................................16

CHAPTER 3: MATERIAL AND METHODS ......................................................18

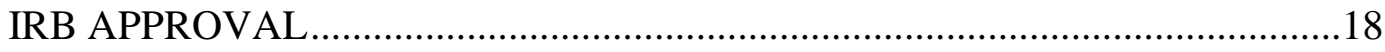







RECRUITING SUBJECTS AND OBTAINING CONSENT .................................19



MEASURING AP POSITION OF MAXILLARY INCISOR ……….................21

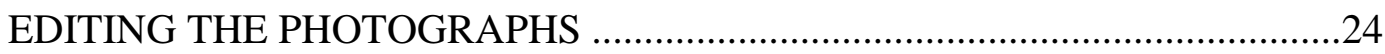

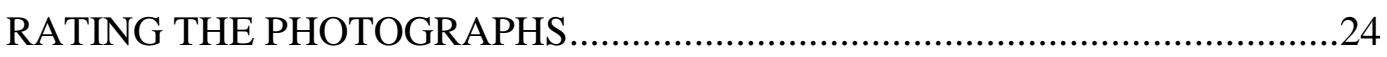

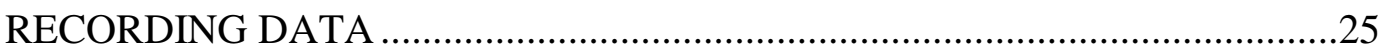

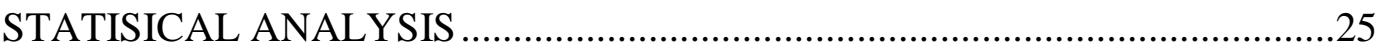





JUDGED ATTRACTIVENESS OF SMILING AND REPOSE ...........................27





SMILING PROFILE RELATIVE TO AP INCISOR POSITION ……………......33

AP INCISOR POSITION AND RATERS OPINION ............................................34

CHAPTER 5: DISCUSSION ...............................................................................................36

DATA COLLECTION AND SAMPLE ANALYSIS ............................................36

ATTRACTIVENESS OF REPOSE AND SMILING PROFILES ….....................36 
ESTHETICALLY OPTIMAL AP INCISOR POSITION

NULL HYPOTHESIS TESTING ........................................................... 40

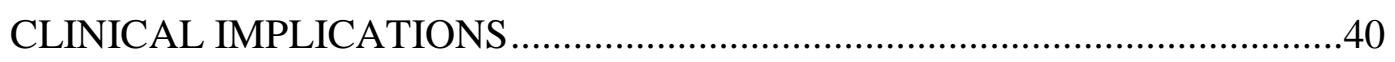

CHAPTER 6: SUMMARY AND CONCLUSIONS .....................................................41

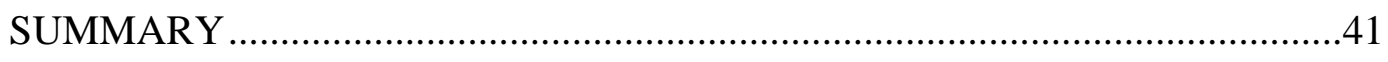

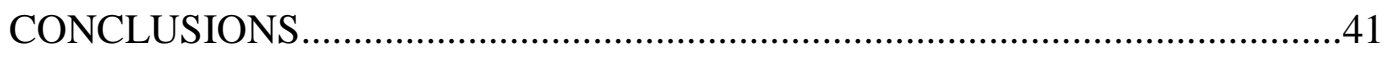

CHAPTER 7: RECOMMENDATIONS FOR FUTURE RESEARCH....................42

RECOMMENDATIONS ON SAMPLE COLLECTION ................................42

RECOMMENDATIONS OF METHODOLOGY .......................................42

REFERENCES....................................................................................................................................43



APPENDIX A - IRB APPROVAL LETTER .........................................48

APPENDIX B - RAW STATISTICS ...................................................50

APPENDIX C - VAS AND SURVEY SAMPLE........................................6. 


\section{LISTS OF FIGURES}

Figure 1: Ricketts' E-plane and Steiner's S-line ......................................................6



Figure 3: Various maxillary incisor inclinations....................................................... 11



Figure 5: Profile angle, nasiolabial angle, and maxillary sulcus ..................................14

Figure 6: Comparison of African American and white profiles ...................................17

Figure 7: Black canvas with twine and laser level .....................................................20

Figure 8: Adjustable millimeter ruler projected from canvas ......................................21



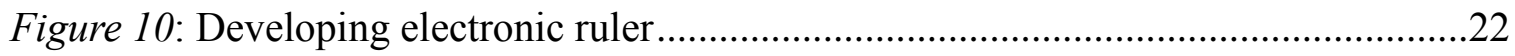



Figure 12: Determining AP position relative to Glabella Vertical ..................................23

Figure 13: Edited repose and smiling profile images ................................................24



Figure 15: Smiling and repose mean ranked VAS score..........................................29

Figure 16: Mean smilng VAS scores compaing orthodontists and non-orthodontists ......30

Figure 17: Mean smiling VAS scores comparing males and females.............................32

Figure 18: Mean Smiling VAS Score and AP Maxillary Incisor Postion ........................33 


\section{LISTS OF TABLES}

Table 1: Photographed subjects and category distribution .........................................27

Table 2: Smiling and repose mean ranked VAS score ..............................................28

Table 3: Mean smiling VAS scores comparing orthodontists and non-orthodontists .......30

Table 4: Mean smilingVAS scores comparing males and females...................................31

Table 5: Multiple comparison for orthodontists and non-orthodontists and profile view .32

Table 6: Multiple comparison for orthodontists VS non-orthodontists and AP position ..33

Table 7: Contingency table of AP incisor category and opinion of incisor position .........34

Table 8: Contingency table of AP incisor category and orthodontists and non-orthodontists

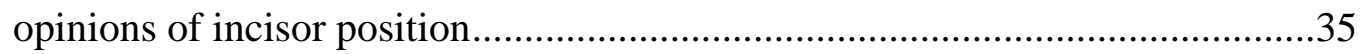




\section{CHAPTER 1: INTRODUCTION}

\section{BACKGROUND \& SIGNIFICANCE}

Evaluating the smiling profile should be a fundamental part of obtaining a complete orthodontic diagnosis. ${ }^{1}$ The soft tissue profile has been studied in abundance. However, there have not been many studies completed to evaluate the esthetics of the smiling profile. Most orthodontists do not routinely assess the relationship of the maxillary incisors directly to a facial landmark from a smiling profile perspective. ${ }^{1}$ Sarver and Ackerman suggest that in order to treat smiles, orthodontists need to visualize and quantify the smile statically and dynamically. They

recommend that records include profile and oblique and frontal smile close-ups. ${ }^{2,3}$ The ultimate position of the anterior teeth has a significant influence on the relationship of the lips and to the facial structure as a whole. The maxillary incisors should be angulated and also positioned most favorably in anterior-posterior and vertical relationships to all facial structures to ensure maximum facial harmony. ${ }^{4}$

Numerous soft tissue analyses have been developed to evaluate the esthetics of the soft tissue lips from a profile prospective. These analyses commonly determine the optimal position of the upper and lower lips relative to the subject's soft tissue chin and nose. Rickett's esthetic plane and the esthetic line of Steiner are widely used by orthodontists during the diagnosis and treatment planning phase of treatment. However, these analyses do not assess the soft tissue from an AP position when the dentition is displayed.

Dr. Larry Andrews has discovered the use of the forehead as a landmark for assessing the AP position of the maxillary central incisors in the smiling profile. ${ }^{5}$ Treatment goals for adult white 
females should include that the maxillary central incisors be positioned somewhere between the forehead's FFA point and glabella and correlated with forehead inclination. ${ }^{1}$

Andrews defined GALL (goal anterior limit line) as a line that parallels the head's frontal plane

and represents the optimal anterior border for the FA point of an Element I maxillary incisor. ${ }^{5}$ A study conducted by Tomblyn found that it is comparable or better to use Glabella Vertical, a vertical line tangent to soft tissue glabella, as a frontal plane compared to FALL. ${ }^{6}$

Additionally, there are currently no standard guidelines in which orthodontists and surgeons agree on when determining the optimal AP position of the maxilla when performing orthognathic surgeries. For example, Posnick stated that the optimal AP position of the maxilla is a range of what is considered proportionate and esthetic, not an exact millimeter number. ${ }^{7}$ Arnett commonly evaluates the patient's profile angle, nasiolabial angle, and maxillary sulcus contour when treatment planning maxillary orthognathic surgery. ${ }^{8,9}$

When comparing the esthetic opinions of orthodontic professionals and lay people, it has been determined that orthodontic professionals can sometimes be more critical of facial and smile esthetics. ${ }^{10}$ It is also important to be aware that cultural and ethnic differences play a role in what a person or population consider esthetic. ${ }^{11}$

There have been no studies that have compared the esthetics of subjects from a lateral perspective in repose and smiling.

\section{STATEMENT OF THE PROBLEM}

Contemporary orthodontic diagnosis and treatment planning does not routinely consist of evaluating the maxillary incisors from a smiling profile prospective. There may be a difference in perceived attractiveness between repose and smiling faces. Additionally, there is no current 
research that identifies the esthetically optimal AP position of the maxillary incisors relative to Glabella Vertical in Caucasian females.

\section{PURPOSE OF THE STUDY}

1. To determine if there is a difference in the rated attractiveness of a smiling and repose profile in Caucasian females.

2. To identify if there is an esthetically optimal AP position of the maxillary incisors in Caucasian females.

\section{NULL HYPOTHESIS}

1. There is no difference in the judged attractiveness between Caucasian females based on smiling profiles versus repose profiles.

2. There is no difference in the AP position of maxillary incisors among most attractively and less attractively rated Caucasian female profiles.

\section{ALTERNATIVE HYPOTHESIS}

1. There is a difference in the judged attractiveness between Caucasian female smiling profiles and repose profiles.

2. There is a difference in the AP position of maxillary incisors among most attractively and less attractively rated Caucasian female profiles.

\section{ASSUMPTIONS}

1. The investigator can reliably position subjects in adjusted natural head posture.

2. Randomly selected subjects and judges are an adequate representation of the Caucasian female population (i.e., inferential statistics). 
3. Age has not compromised facial esthetics of study group.

4. Gray-scale images may minimize the influence of other facial features such as complexion and hair color on perceived attractiveness.

\section{LIMITATIONS}

1. Other facial features may influence raters' judgment of subjects' attractiveness.

\section{DELIMITATIONS}

1. The majority of randomly chosen raters will be young adults.

2. The majority of faculty and orthodontic residents have been trained to evaluate the AP position of the maxillary incisors.

\section{CHAPTER 2: REVIEW OF THE LITERATURE}

\section{FACIAL ESTHETICS}

When trying to determine the esthetically optimal anteroposterior position of the maxillary incisors it is important to understand facial esthetics as a whole. The face is perceived as the most important physical characteristic in the development of self-image and self-esteem. People who are satisfied with their faces appear to be more self-confident and have higher self-esteem than those who are dissatisfied. ${ }^{12}$ It has been discovered by many researchers that improving dental esthetics is the main motivational factor for undergoing orthodontic treatment ${ }^{13,14}$ Most people view orthodontic treatment as a way to improve their dentofacial appearance. ${ }^{15}$

The facial profile as depicted by artists has strongly influenced plastic surgeons and their creative ability to rebuild a severely damaged face and correct congenital facial defects. ${ }^{16}$ Farkas and 
colleagues completed a study in which they compared basic profile inclinations in young Caucasian women to the profile inclinations from sculptures and sketches throughout history. ${ }^{16}$ They found that the majority of Ancient art pieces had receding profiles with receding upper face and upper lip. Renaissance art displayed milder recession of the lower face, while modern art exhibited an almost vertical profile with a protruding upper lip. ${ }^{16}$

Cosmetic dentists have long been interested in understanding smile esthetics. A panel of orthodontists, plastic surgeons, artists and general dentists found that patients with class I occlusion with or without extractions had no evaluated difference in rated smile esthetics. ${ }^{17}$ Additionally, maxillary gingival display and position of the anterior teeth had a definite effect on smile esthetics. ${ }^{17}$ Prosthodontists are also aware of the influence the dentition has on the soft tissue profile. The presence of anterior artificial teeth affects the contour of the lips and nose. Prosthodontists frequently evaluate the nasiolabial angle and Rickett's esthetic plane when examining the soft tissue profile. ${ }^{18}$

Orthodontists have long been fascinated by the perceptions of a balanced profile. In 1970, Peck and Peck stated that the orthodontic community had largely neglected to study the public's esthetic viewpoint. They also referred to the lateral profile view as the most significant aspect of the face orthodontically. ${ }^{19}$ Another study found that if the soft tissue profile is digitally morphed to be average the subjects are rated as more attractive. ${ }^{20}$ Studies have constructed various profile silhouettes and found excessive lip protrusion acceptable in males and females when there is either a large nose or large chin present. ${ }^{21}$ Profit also explained that an upper lip that inclines backward relative to the true vertical line, as a result of retraction of the maxillary incisors, tends to compromise facial esthetics. Additionally, a poorly-defined labiomental sulcus can detract from facial esthetics when lip strain is required to bring the lips together. ${ }^{22}$ Facial esthetics 
should have a higher priority in the treatment planning process, and should be evaluated early in the treatment planning process. $^{20}$

\section{CONVENTIAL SOFT TISSUE ANALYSES}

Multiple soft tissue analyses have been developed to help determine facial harmony in various patients. Robert Ricketts developed the Esthetic plane or E-plane in 1960. The esthetic plane runs from the tip of the nose to the soft tissue pogonion. ${ }^{23}$ The upper lip should lay $4 \mathrm{~mm}$ posterior to the E-plane and the lower lip should lay $2 \mathrm{~mm}$ posterior to the E-plane. When the lips protrude ahead of these dimensions they have been perceived as creating facial disharmony. ${ }^{23}$

Cecil Steiner established the esthetic plane of Steiner, or S-line, which is a line connecting the midpoint of columella to soft tissue pogonion. According to Steiner, the lips should fall on this line. Deviation from this line is considered protrusion or retrusion of the upper and lower lips. ${ }^{24}$
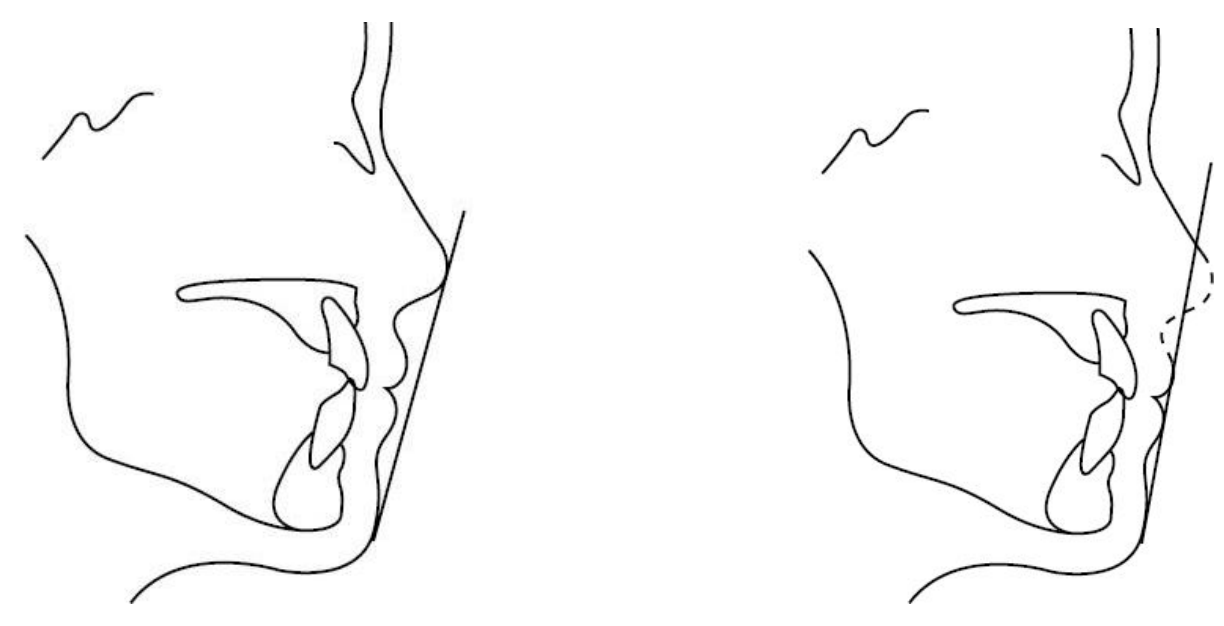

Figure 1: Ricketts' E-plane (left) and Steiner's S-line (right).

In 1981 Reed Holdaway stated that most orthodontists have had the unpleasant experience of finding that some patient's faces looked worse after orthodontic treatment was completed. His soft tissue analysis included a measurement for the superior sulcus depth, which was measured 
from a line perpendicular to Frankfort Horizontal and tangent to the vermillion border of the upper lip. ${ }^{25}$ Holdaway suggested a range from $1-4 \mathrm{~mm}$ with $3 \mathrm{~mm}$ being ideal. Utilizing this measurement when treatment planning it should help reduce the over retraction of the anterior teeth. $^{25}$

\section{SKELETAL DIAGNOSIS USING SOFT TISSUE}

Research has shown that for most orthodontic treatment planning decisions the availability of a lateral cephalometric radiograph and tracing did not make a significant difference to the eventual treatment decision. ${ }^{26}$ In 1982, Fields discovered that soft tissue outlines from profile radiographs, with or without supplementary photographs, do not provide enough information to reliably assess the underlying skeletal pattern in children 8 and 12 years old. ${ }^{27}$ Additionally, prognathic patterns were not as readily identified as retrognathic patterns. ${ }^{27}$ With the recent concerns with ionizing radiation and radiographic exposure guidelines, Masoud proposed using dentofacial photogrammetry instead of cephalometric radiography and using the eyes as a reference instead of the cranial base structures ${ }^{28}$ Important treatment planning decisions, such as extractions and orthognathic surgery, were found to have substantial agreement between the traditional cephalometric and photogrammetry methods. ${ }^{28}$ It has been suggested that 3D dentofacial photogrammetry in conjunction with a panoramic radiograph can eliminate the need

for a cephalometric radiograph in cases with crowding or spacing and a near Class I occlusion. ${ }^{28}$

\section{SIX ELEMENTS ORTHODONTIC PHILOSOPHY}

Larry Andrews developed The Six Elements Orthodontic Philosophy in the 1980's. The Six Elements Orthodontic Philosophy is a comprehensive approach to orthodontics which includes diagnosis, positionally correct classification, and treatment based on the Six Elements of 
Orofacial Harmony. ${ }^{5}$ This philosophy utilizes specific goals, objects, landmarks, and referents to achieve optimal diagnosis and outcomes. The six elements include: (I) optimal tooth and arch characteristics, (II) optimal AP jaw positions, (III) optimal jaw widths, (IV) optimal jaw heights, (V) optimal chin prominence, and (VI) optimal occlusion. This classification system does not use cephalometric norms to diagnosis and treatment plan. ${ }^{5}$ The Six Elements Philosophy includes evaluating the lateral smiling profile, which has been described as a paradigm shift from the traditional soft tissue analysis (Andrews). ${ }^{5}$

In Element I, the root end of each tooth's long axis is centered over basal bone from a parasagittal jaw perspective and each crown is inclined so that occlusion can be optimal. ${ }^{5}$ According a study completed by Andrews where he evaluated 120 casts of naturally optimal occlusion, he discovered the maxillary inclination was on average positive 7 degrees in reference to the occlusal plane. ${ }^{29}$

To expand on Element II, the objective of this Element is to evaluate the anteroposterior position of the maxillary and mandibular jaws. ${ }^{30}$ The forehead anterior limit line (FALL) and goal anterior limit line (GALL) are reference planes that are used to evaluate the anteroposterior position of the maxillary incisors from a smiling profile prospective. GALL is determined by the forehead shape and inclination. ${ }^{30}$ The forehead can be classified as round, straight or angular. There are three references points of the forehead that should be identified. They are trichion (the junction of the forehead and the anterior hairline), superion (the most superior aspect of the clinical forehead), and glabella (the most anterior projection of the anterior forehead). ${ }^{7}$ The previously mentioned three points are then used to locate the forehead anterior point (FFA point), which is the midpoint between the superion and glabella. FALL is vertical reference plane that runs through the FFA point and is perpendicular to the floor when the patient is positioned in 
natural head posture. Additionally, GALL is determined by incorporating forehead inclination. The formula used is to determine the location of GALL in reference to FALL is (forehead inclination angle -7$) \times 0.6=$ mm. ${ }^{7}$ Once GALL is established the anteroposterior position of maxilla and mandible can be evaluated. . An optimal Element II maxilla requires the FA point (the point on the facial axis of the clinical crown that is midway between the gingival and occlusal borders) of an Element I maxillary central incisor lie on GALL. ${ }^{30}$

The maxilla can be classified as black (retrognathic), green (orthognathic), or red (prognathic) by measuring the distance from the FA point of an Element I maxillary incisor to the GALL. Mandibular AP Position is optimal when in centric relation the mandibular incisors are Element I and occlude optimally with Element I maxillary incisors of an optimal Element II maxilla. ${ }^{30}$



Figure 2: Andrew's Element II. ${ }^{30}$

When the FA point of the Element I maxillary incisor lies on the GALL the maxilla is classified as green (orthognathic). To expand, if the FA point of the Element I maxillary incisor is 4 millimeters anterior to GALL, the patient's maxilla is categorized as R4 (prognathic) and if the 
FA point of the Element I maxillary incisor is 2 millimeters posterior to GALL the patient is categorized as B2 (retrognathic).

\section{SMILING PROFILE}

Smiling esthetics, especially frontal smiling esthetics has been comprehensively studied. However, there are only a limited number of studies that evaluated the esthetics of the smiling profile. Saver and Ackerman acknowledged that the smile should not only be viewed from a frontal view, but the smile should also be analyzed by the lateral view. Both frontal and lateral perspectives have a significant role in smile composition. ${ }^{2,3}$ Overjet and incisor inclination are best viewed in the sagittal dimension. It is very important for orthodontists to analyze the smile from a lateral perspective because excessive positive overjet is one of the dental traits most recognizable by the lay person. ${ }^{2,3}$ Cao stated that evaluating the smiling profile is a fundamental part of a comprehensive orthodontic diagnosis. ${ }^{31}$ Treatment planning to a dynamic smiling profile is more aesthetic in nature than treatment planning to a repose profile. ${ }^{32}$ It is important to assess the AP conditions from the profile with the maxillary incisors displayed, as when broadly smiling. ${ }^{32}$

The American Board of Orthodontists does not currently require a lateral smiling photograph as part of their requirements for orthodontic records.

The maxillary incisors should be inclined and also positioned most favorably in anteriorposterior and vertical relationships to all facial structures to ensure maximum facial harmony. ${ }^{4}$ Numerous studies have compared the most esthetic inclination of the maxillary incisors. One study found that incisors with inclination above normal standard values were considered more esthetic. ${ }^{33}$ However, the results of another study revealed that maxillary incisors that are upright 
or have slight lingual inclinations were preferred. ${ }^{31}$



Figure 3: Various maxillary incisor inclinations. ${ }^{31}$

Therefore, there have been conflicting results on the optimal inclination of the maxillary incisors from a lateral perspective.

Will Andrews suggested that since the incisors are considered part of the face, the orthodontist should evaluate the facial profile with maxillary incisors bared. He studied photographs of adult white females with good facial harmony and found that in white females with harmonious profiles the maxillary incisors were positioned between the Forehead's Facial Axis Point (the midpoint of the clinical forehead) and soft tissue glabella in $93 \%$ of the sample. ${ }^{1}$ He concluded that the forehead is an important landmark for AP maxillary incisor positioning in adult white females. ${ }^{1}$ Andrews also stated that there is no reliable correlation between the nasiolabial angle and the position of the maxillary incisors in a profile view. ${ }^{1}$

One study used the computer to digitally move the location of the maxillary incisors forward and backward in $1 \mathrm{~mm}$ increments. ${ }^{34}$ Orthodontist and non-orthodontists scored the attractiveness of the photographs using a visual analog scale. Photographs in which the incisors were maximally retracted were rated the least desirable, which suggests it is not esthetically desirable to retract 
the maxillary anterior teeth. ${ }^{34}$ The study also concluded that Andrew's Element II is a good method to evaluate attractiveness of the maxillary incisor position. ${ }^{34}$

\section{GLABELLA VERTICAL}

A study by Ellis in 2017 used the computer to digitally alter the AP position of the soft tissue glabella. ${ }^{35}$ The original, unaltered photographs with the maxillary incisors anterior to the soft tissue glabella were perceived as most attractive. The photographs with the most extreme anterior movement of the soft tissue glabella $(6 \mathrm{~mm})$ were judged as least attractive. ${ }^{35}$ This study suggests that changes in the position of the soft tissue glabella can impact the appreciation of facial attractiveness. ${ }^{35}$ Additionally, these results do not support the proposal that maxillary incisors should not be positioned anterior to the soft tissue glabella. ${ }^{35}$

The term Glabella Vertical was first defined in unpublished research by Tomblyn. ${ }^{6}$ Glabella Vertical is a frontal reference plane that can be used to locate GALL, the goal anterior limit line. Glabella Vertical is a line that parallels the head's frontal plane in Natural Head Orientation and passes through the soft tissue glabella point. ${ }^{6}$ This study revealed that GALL is located $-1 \mathrm{~mm}$ to 0mm from glabella in $95 \%$ of the population. ${ }^{6}$ Therefore, it has been proposed that Glabella Vertical can be used in place of FALL, the Forehead's Anterior-Limit Line, which passes through the Forehead's Facial Axis point, FFA. ${ }^{6}$ Using Glabella Vertical as the facial plane to determine the AP position of the maxillary incisors differs from the traditional Six Elements Orthodontic Philosophy because it does not account for forehead inclination. 




Figure 4: Glabella Vertical. ${ }^{6}$

\section{SURGICAL TREATMENT PLANNING OF MAXILLA}

The bite indicates a problem; the face indicates how to treat it. ${ }^{8,9}$ Many oral surgeons have explained that reliance on cephalometric analysis alone during treatment planning can sometimes lead to esthetic problems and the final outcomes can be less than desired. ${ }^{8,9}$ Posnick stated that the "ideal" aesthetic horizontal position of the maxilla is not an exact millimeter number, but a narrow range of what is considered proportionate. ${ }^{7}$ Normative cephalometric measurements, such as ANB, generally underestimate the desired horizontal aesthetic projection of the maxilla and should not be relied upon. ${ }^{7}$

Arnett commonly assesses the patient's profile angle, nasiolabial angle, and maxillary sulcus contour when treatment planning maxillary orthognathic surgery. ${ }^{8,9}$ The profile angle, which is 
formed by connecting the soft tissue glabella, subnasle, and soft tissue pogonion, should be between $165^{\circ}$ to $175^{\circ} .^{8,9}$ Surgical procedures should be completed to address an imbalance that does not fall in this range. The nasiolabial angle, formed by the intersection of the upper lip anterior and columella at subnasle should be $85^{\circ}$ to $105^{\circ} .{ }^{8,9}$ If the nasiolabial angle is obtuse retraction of the anterior dentition orthodontically or surgically should be avoided. Finally, the maxillary sulcus contour should be gently curved. ${ }^{8,9}$


Figure 5: Profile angle (left), nasiolabial angle (middle), maxillary sulcus (right). ${ }^{8,9}$

\section{NATURAL HEAD POSTURE}

Natural head posture (NHP) is the usual, balanced position of the head which is adopted for viewing the horizon or an object at eye level. ${ }^{36}$ NHP is determined by many physiological factors such as visual righting reflexes, reflexes initiated by earth's gravity and muscular proprioceptive stimuli, personality, and emotions. ${ }^{36}$ NHP is a physiological position and can be considered to represent the aesthetic and functional anatomic form of the craniofacial complex. ${ }^{36}$ Moorees concluded that the vertical, or a horizontal perpendicular to it, is preferable to reference lines within the cranium, because the biological variation of intracranial lines is greater than the variation in registration of natural head position. ${ }^{37}$ 
NHP reproducibility refers to how consistently a subject can reproduce the same head position on different occasions. Peng found NHP to have $1.8^{\circ}$ variance with 5-10 minute

reproducibility. ${ }^{38}$ Studies have shown the variance of NHP after five years to be approximately $3^{\circ}$, which is significantly less than the variance of intracranial reference planes. ${ }^{38,39}$ Therefore, cephalometric analyses utilizing NHP remain valid over time.

\section{VISUAL ANALOG SCALE}

Visual analog scale (VAS) is one of the most popular and widely used methods to assess esthetic concepts. ${ }^{10}$ It has been used in numerous published studies to evaluate profiles, faces, and tooth positions. One of the major advantages of VAS is that it is relatively simple and inexpensive. ${ }^{10}$ Futhermore, it has been suggested to rank the photographs for each rater, instead of using the number measured on the VAS, this will provide a "location-free" measure of facial attractiveness. ${ }^{10}$ A recent study concluded that VAS is a reliable method to use when dentists, orthodontists, and lay people evaluate the attractiveness of photographs of teeth and lips. ${ }^{41}$ Ranking photographs as judged by clinicians and non-clinicians can be used as a standard against which facial attractiveness can be assessed. ${ }^{42}$

\section{EXTRACTION VERSUS NON-EXTRACTION}

Numerous studies have been completed that compare the esthetic effect of extraction and nonextraction treatment on the soft tissue profile. The relative contraindications for extraction treatment are deep bite, horizontal growth type, concave lip profile and prominence of the nose. ${ }^{43}$ Bowman and Lysle randomly studied the pre and posttreatment profiles of extraction and nonextraction Caucasian patients. Their sampled showed a "flatter" profile by an average of $1.8 \mathrm{~mm}$ in the extraction sample, while non extraction treatment has little effect on the profile. ${ }^{44}$ 
Research has also shown no significant soft tissue profile differences were found between extraction and non-extraction patients when the patients were initially treated to the same incisor position. ${ }^{45}$ Additional research has suggested that in most extraction cases the lip profile becomes more concave than in non-extraction patients. However, in most cases the amount of retraction of the lips is small and clinically irrelevant. ${ }^{43}$

\section{VARIABILITIES IN RATED ATTRACTIVENESS}

Multiple studies have shown that dentists tend to be more sensitive in their judgement of facial attractiveness than lay persons. ${ }^{10,19,20,46}$ This may be due the dentists' educational background, training, and knowledge of facial impairments. ${ }^{46}$ However, additional studies have also revealed agreement in the judgement of facial attractiveness between lay judges and clinicians. ${ }^{42}$ Lay judges may tend to concentrate on other extrinsic facial features such as chin shape and size, shape of the nose, hair color and style, etc., which can influence the perception of attractiveness. ${ }^{47}$ Interestingly, adolescents have been shown to be more tolerant of variations of facial profile when compared to adults. ${ }^{46}$

Ethnic and racial differences play a major role in diversifying esthetic preferences. ${ }^{11}$ An objective for the orthodontist should be to treat to ideal; however, the expectations of the patient must be considered because ideals of esthetic profiles may vary. ${ }^{48}$ Several factors such as sex, education, socioeconomic status, and geographic location affect the esthetic preferences of the public. ${ }^{11}$ One of the main objects of orthodontic treatment is to improve patient's appearance. In order to be successful at this, orthodontists need to understand what the patient perceives to be attractive. 
Turkkahraman studied the judged attractiveness of males and females and found that fuller and more protrusive lips were judged more attractive in females and retrusive lips with a prominent nose and chin were more admired in males. ${ }^{11}$ It has also been noted that people's own profiles can affect his or her profile preferences. ${ }^{11}$ One study found that attractive Caucasian models on average had a straighter profile, while the African American models commonly had fuller, more prominent lips. ${ }^{49}$ Hall found that African American and white orthodontists and laypersons preferred greater skeletal convexity at A-point for African American profiles than for white profiles. $^{48}$



Figure 6: Comparison of African American and white profiles. ${ }^{49}$

It has also been described that in females a bimaxillary alveolar protrusive profile with thicker lips is generally preferred, and in males the bimaxillary retrusive profile with flat lips and a prominent chin is preferred. ${ }^{50}$ A study was completed in various regions of Turkey to try and determine the most esthetic facial profiles. ${ }^{51}$ However, there was significant difference in the measurements between the various regions and it was concluded that the search for universal standards of facial profiles is inconclusive. ${ }^{51}$ It is important to research the facial norms of differing geographical areas. 


\section{CHAPTER 3: MATERIALS AND METHODS}

IRB APPROVAL

Approval for expedited research was obtained from West Virginia University Institutional

Review Board prior to the start of this study (See Appendix A).

\section{SAMPLE DESCRIPTION}

There were 30 photographed subjects and 32 raters in this study. The raters included 6 male orthodontic faculty/residents, 6 female orthodontic faculty/residents, 10 male non-orthodontic professionals, 10 female non-orthodontic professionals.

\section{PHOTOGRAPHED SUBJECTS}

Inclusion Criteria

- Caucasian female

- $18-30$ years of age

Exclusion Criteria

- Craniofacial abnormalities

- Severely rotated maxillary incisors

- Receiving active orthodontic treatment

\section{RATERS}

Inclusion Criteria 
- Male or female West Virginia University School of Dentistry orthodontic faculty or resident

- Male or female non-orthodontic professional

- HIPAA training

\section{RESEARCH DESIGN}

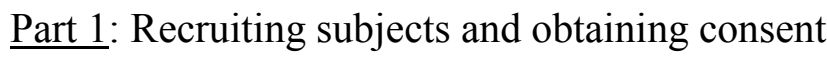

Caucasian females that presented to the WVU School of Dentistry Orthodontic Department for an appointment or that accompanied patients to his/her appointment that were not currently receiving active orthodontic treatment and had no orthodontic appliances on the facial surfaces of the dentition were randomly recruited to be photographed for the study. The purpose, design, and potential risks of the study were briefly explained to the prospective subjects. The prospective subjects were given the opportunity to read the Informed consent with HIPAA form and ask questions. Once the subject agreed to participate the informed consent was signed.

The prospective raters included non-orthodontic professionals with previous HIPAA training. The purpose, design, and potential risks of the study were briefly explained to the perspective raters. The perspective raters were given the opportunity to read the Informed consent without HIPAA form and ask questions. The raters were informed that they would be seeing facial photographs and the identity of the photographed subjects must remain confidential. Once the rater agreed to participate the informed consent was signed. 
Part 2: Capturing the photograph

A laser level was used to project lines parallel and perpendicular to the floor. The lines were transferred to a black canvas using white twine that was attached to the sides of the canvas.



Figure 7: Black canvas with twine and laser level.

The photographed subject was positioned in front of the black canvas in adjusted natural head posture facing anatomic left. The camera was placed on a tripod that was level to the floor and positioned 4 feet from the canvas. The camera was sited perpendicular to the wall at the maxillary incisor to avoid parallax. A millimeter ruler was projected from the wall. The ruler was then adjusted to align with the subject's midsagittal plan. This was achieved by measuring the distance from the canvas to subject's midsagittal plan and adjusting the ruler to be the same distance from the canvas. 


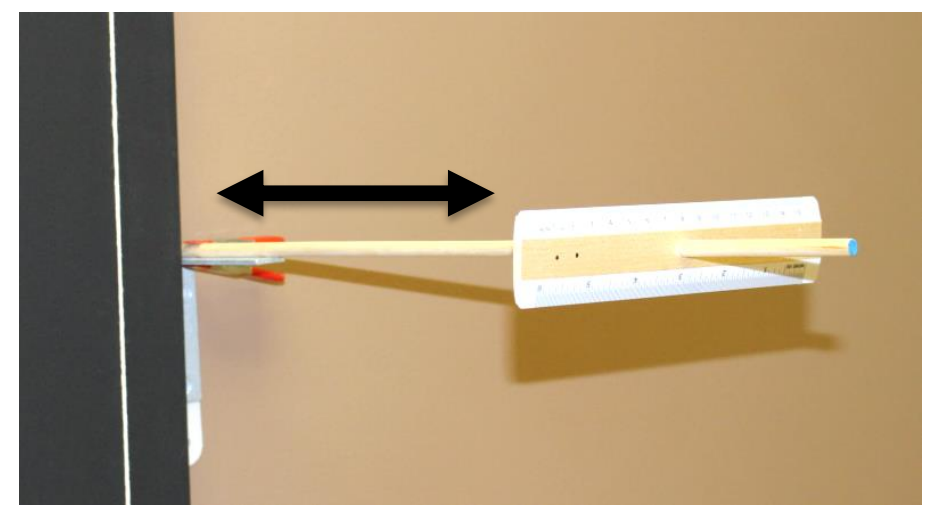

Figure 8: Adjustable millimeter ruler projected from canvas.

The photographs were captured using a Canon Rebel SL1 with a $0.25 \mathrm{~m}$ macro lens with flash. The subject was asked not to smile and an image was captured. The subject was asked to smile and a second image was captured.

Part 3: Measuring AP position of the maxillary incisor relative to Glabella Vertical Images were uploaded to Microsoft PowerPoint ${ }^{\mathrm{TM}}$. In PowerPoint, a vertical line parallel to the vertical line on the canvas was added. The line was positioned tangent to the subject's soft tissue glabella. The line was referred to as Glabella Vertical. 


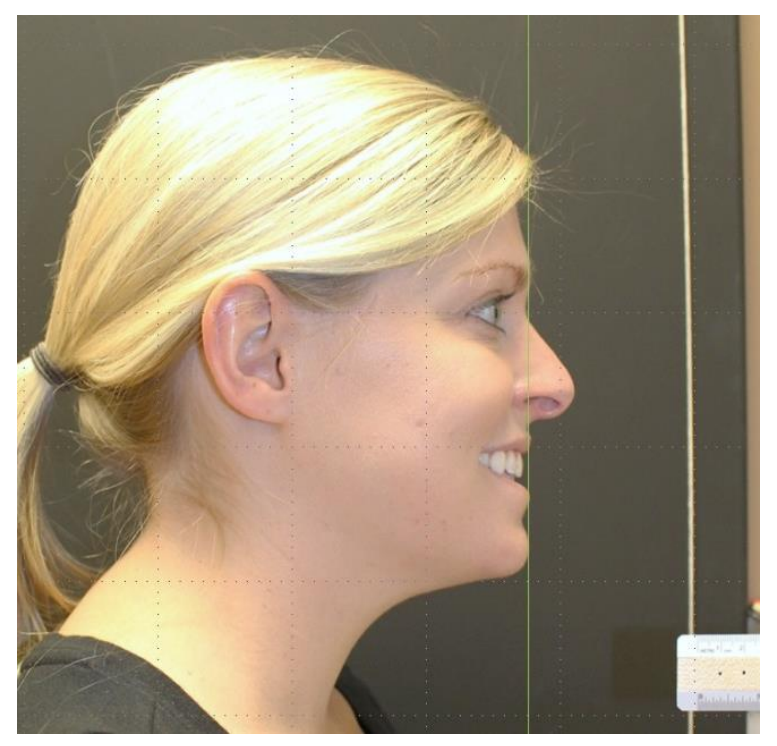

Figure 9: Adding Glabella Vertical.

A magnified, focused photograph of the ruler was taken. An "electronic ruler" was fabricated in Microsoft PowerPoint ${ }^{\mathrm{TM}}$ by adding lines in $1 \mathrm{~mm}$ intervals that correspond to the marks on the ruler.



Figure 10: Developing electronic ruler.

The "electronic ruler" was then placed on the smiling photographs and calibrated using the two black dots on the ruler in the smiling profile photographs. 



Figure 11: Calibrating electronic ruler.

The "electronic ruler" was then positioned on the FA point of the maxillary incisors. The distance from the FA point of the maxillary incisor to Glabella Vertical was measured and recorded.
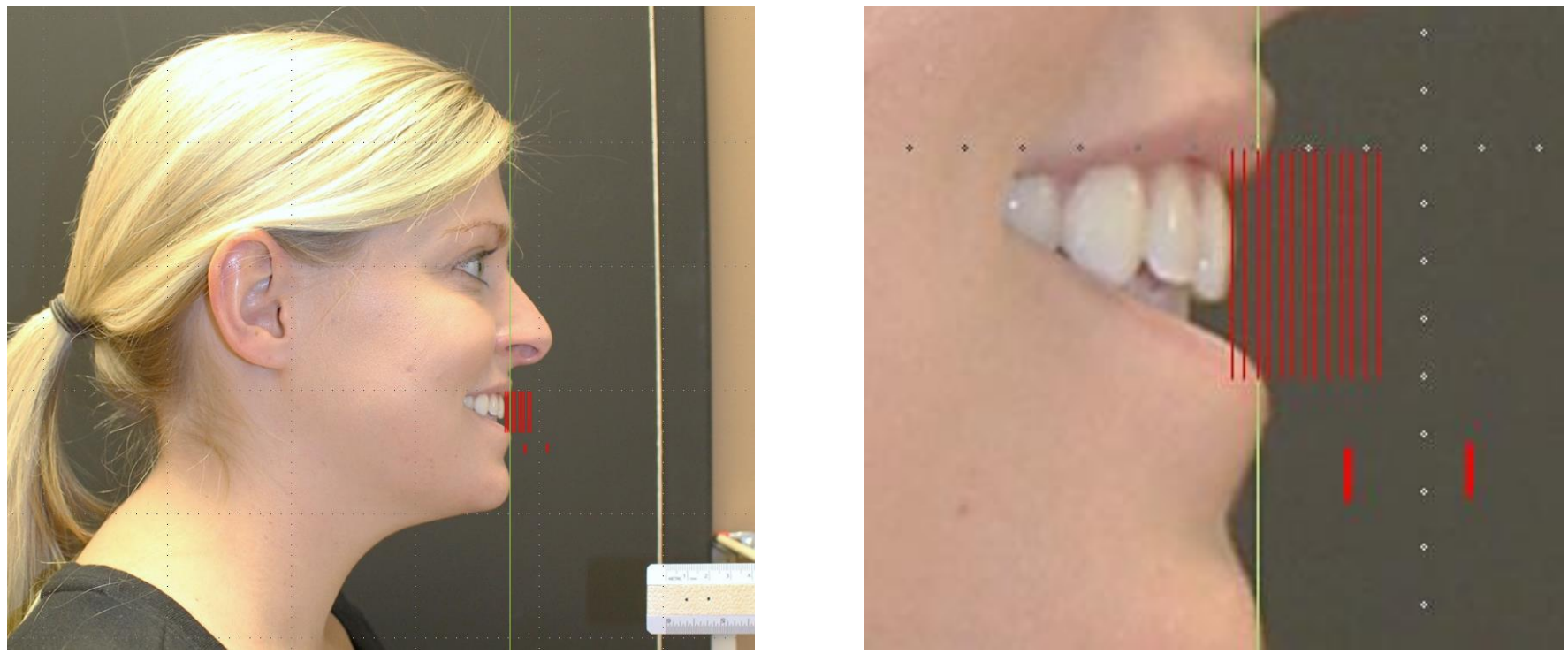

Figure 12: Determining AP position relative to Glabella Vertical. 


\section{Part 4: Editing the photographs}

The smiling and repose photographs were digitally edited by cropping out the ruler and vertical lines on the canvas. The photographs were also altered to be black and white. The images were randomly numbered and saved in a PowerPoint presentation on a USB drive.

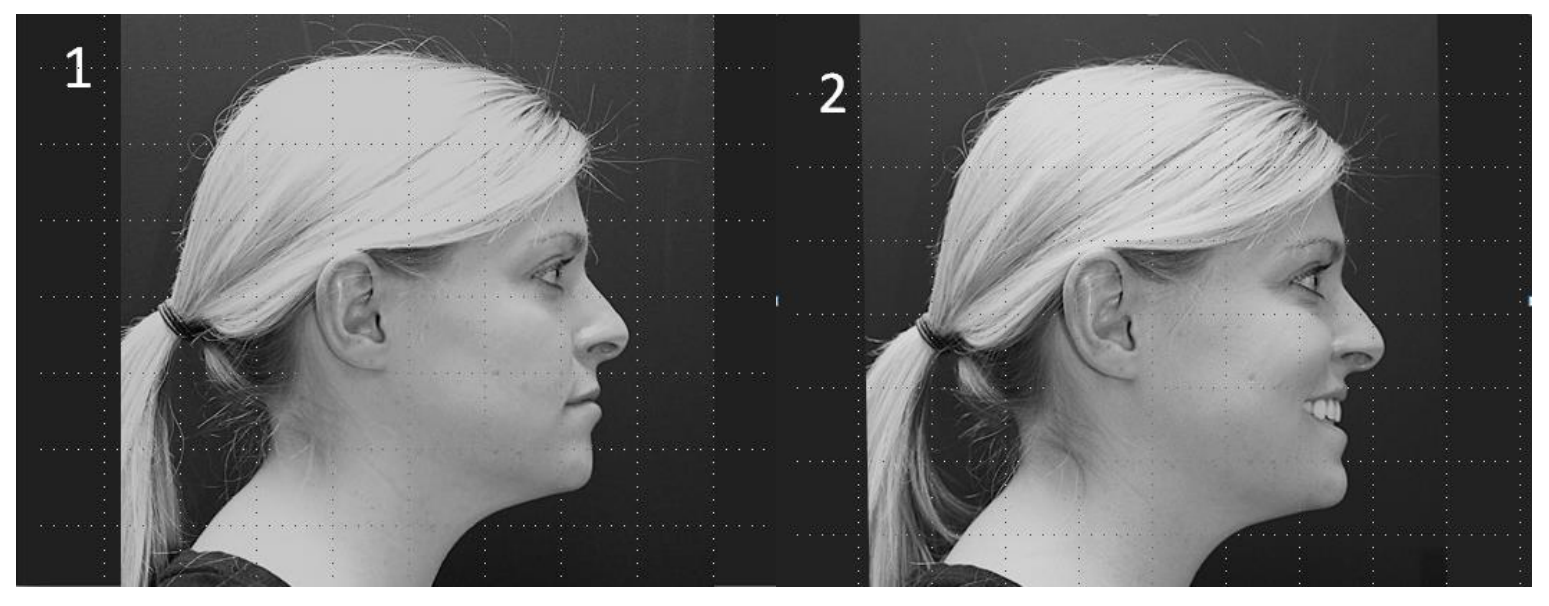

Figure 13: Edited repose (left) and smiling (right) profile images.

Part 5: Rating the photographs

The raters included 6 male orthodontic faculty/residents, 6 female orthodontic faculty/residents, 10 non-orthodontic male professionals, and 10 non-orthodontic female professionals. Raters were shown the photographs in the WVU Orthodontic conference room. Each of the 60 photographs (30 smiling and 30 repose) was projected on the television screen for 15 seconds. The rater was given a packet of paper which included $60-100 \mathrm{~mm}$ Visual Analog Scales. The raters were informed that they were to evaluate the attractiveness of the profiles, particularly the area of the mouth in the smiling and repose photographs and mark on " $\mathrm{X}$ " on the line 
corresponding to the rated attractiveness. Additionally, for each of the 30 smiling lateral photographs the raters were shown the same 30 smiling photographs for an additional 15 seconds and asked to circle if they would prefer the upper front teeth to stay in the current position, come forward, or move backward.

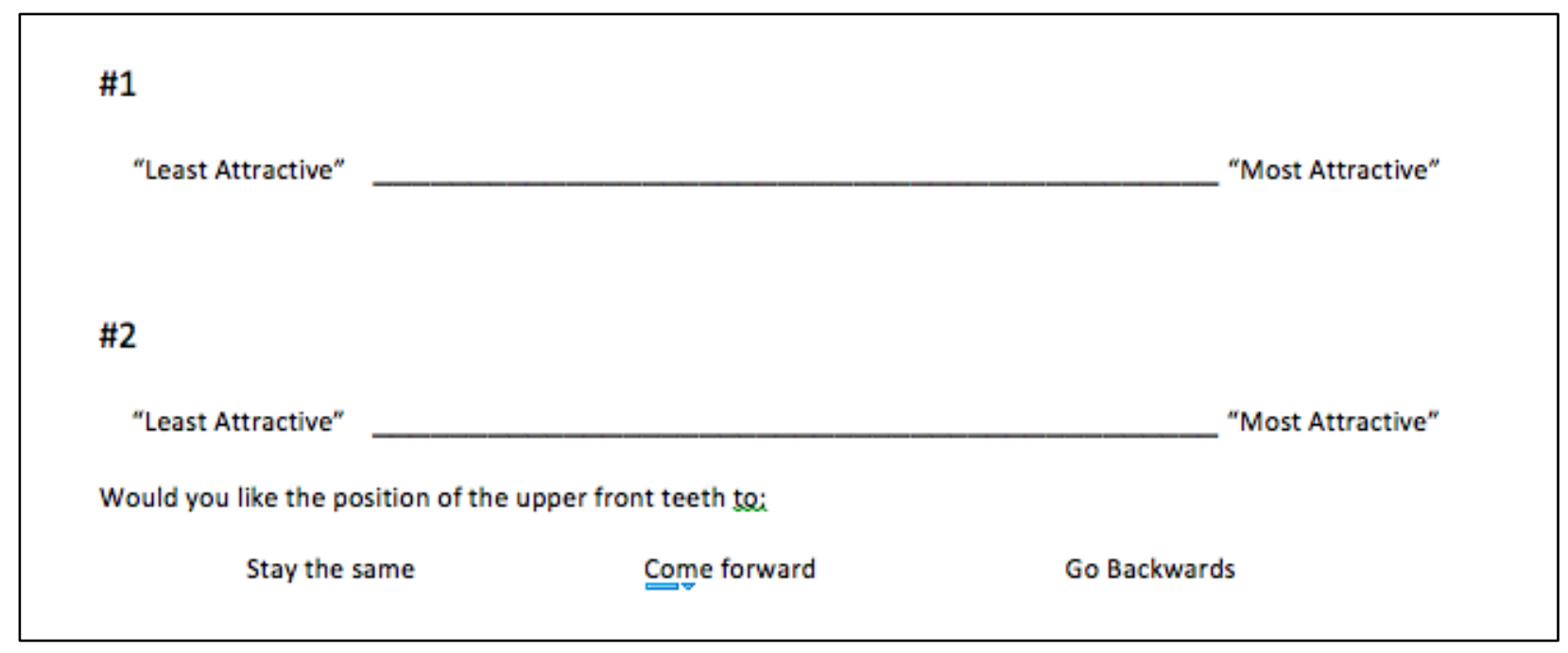

Figure 14: Visual analog scale

\section{Part 6: Recording Data}

Each of the visual analog scales was measured using a millimeter ruler, with zero being placed on the left end of the line closest to least attractive. The measurements were then recorded and entered into a Microsoft Excel ${ }^{\mathrm{TM}}$ workbook.

\section{Part 7: Statisical Analysis}

All statistical tests were conducted using SAS (version 9.4, 2013, SAS institute Inc, Cary, NC).

To examine the effect of profile view (repose and smiling) on the subject's perceived attractiveness; each subject's ranking scores were analyzed separately since it was assumed there is a difference in individual facial attractiveness. A mixed model analysis was performed to 
evaluate the effects of profile view (repose vs. smile), panel (orthodontist vs. non orthodontist), gender (male vs. female), and rater nested within panel on perceived attractiveness. Rater was considered as a random effect and all others as fixed effects. The interaction between panel and view and between gender and view were also added to the model as the focus was on the effect of the view and the two interaction term. Tukey's test was performed for multiple comparisons after a significant interaction effect. A paired t-test was conducted to examine the difference in facial attractiveness ranking scores between the repose and smiling profile. The mean difference in facial attractiveness between orthodontists and non-orthodontists, males and females was examined using a two sample t-test.

To examine the effect of the AP position of the maxillary incisor on perceived attractiveness, only the attractiveness ranking scores for the smiling profile was used analyzing all subjects' ranking scores together. The mixed model analysis was performed to evaluate the effects of AP incisor position (green vs. black vs. red), panel (orthodontist vs. non-orthodontist), gender (male vs. female), rater nested within panel and subject on perceived attractiveness. Rater and subject were treated as two random effects and all others as fixed effects. The interaction between panel and AP incisor position and between gender and AP incisor position were also incorporated in the model. Tukey's test for multiple comparisons after a significant interaction effect was utilized. To compare the mean difference in attractiveness ranking scores among different AP incisor positions for individual raters, a one way analysis of variance (ANOVA) test was used and Tukey's test was performed for multiple comparisons after a significant test result.

To analyze the association between AP incisor position and raters' opinion on whether the teeth should be moved backward, forward or stay the same, chi-square analysis was used. The 
Cochran-Mantel-Haenszel statistic was also utilized to determine the association between AP incisor position and raters' opinion adjusted for different strata.

All statistical tests were two-sided and $p$-values $<.05$ were considered statistically significant.

\section{CHAPTER 4: RESULTS}

\section{DATA COLLECTION}

The random sample of photographed subjects included 18 subjects with category black (retrognathic) maxillary incisors, 4 subjects with category green (orthognathic) maxillary incisors, and 8 subjects with category red (prognathic) maxillary incisors. The subjects' incisor position relative to Glabella Vertical ranged from B13 (13 mm posterior to Glabella Verical) to R8 (8 $\mathrm{mm}$ anterior to Glabella Vertical).

Table 1: Photographed subjects and category distribution.

\begin{tabular}{|l|l|}
\hline Category & No. of subects \\
\hline Black (Retrognathic) & 18 \\
\hline Green (Orthognathic) & 4 \\
\hline Red (Prognathic) & 8 \\
\hline
\end{tabular}

\section{JUDGED ATTRACTIVENESS OF SMILING AND REPOSE}

In 15 out of the 30 subjects there was a statistically significant difference between the mean repose ranked VAS scores and the mean smiling ranked VAS scores. (See Table 2 below.) In 5 of the subjects the mean repose ranked VAS score was statisically significantly higher that that 
the mean smiling VAS score. These 5 subjects were catergorized as R1, R4, R2, B9, and B9 in relation to Glabella Vertical. In 10 of the subjects the mean repose ranked VAS score was statistically significantly lower that the mean smiling ranked VAS score. Additionally, 3 out of 4 of the subjects catagorized as G (green) in relation to Glabella Vertical had a statisically significant higher mean smiling ranked VAS score when compared to their mean repose ranked VAS score.

Table 2: Smiling and repose mean ranked VAS score.

\begin{tabular}{|c|c|c|c|c|c|c|c|}
\hline \multirow[t]{2}{*}{ Subject } & \multirow{2}{*}{$\begin{array}{l}\text { Distance } \\
\text { from } \\
\text { GV }\end{array}$} & \multirow[t]{2}{*}{ Category } & \multicolumn{2}{|c|}{ REPOSE } & \multicolumn{2}{|l|}{ SMILE } & \multirow[t]{2}{*}{ p-value } \\
\hline & & & MEAN & SD & MEAN & SD & \\
\hline 1 & 1 & $\mathrm{R}$ & 46.4 & 13.6 & 21.1 & 14.9 & $<.0001^{*}$ \\
\hline 5 & -8 & $\mathrm{~B}$ & 17.8 & 13.6 & 42.1 & 14.6 & $<.0001 *$ \\
\hline 6 & -1 & B & 8.8 & 7.1 & 22.6 & 13.6 & $<.0001 *$ \\
\hline 8 & -9 & $\mathrm{~B}$ & 37.1 & 16.1 & 27.1 & 15.7 & $0.03 *$ \\
\hline 11 & 4 & $\mathrm{R}$ & 12.7 & 10.0 & 5.6 & 4.4 & $<.0001 *$ \\
\hline 13 & -9 & $\mathrm{~B}$ & 35.6 & 15.3 & 14.0 & 14.9 & $<.0001^{*}$ \\
\hline 15 & -6 & B & 42.0 & 12.7 & 47.9 & 10.4 & $.04 *$ \\
\hline 16 & 2 & $\mathrm{R}$ & 42.3 & 15.2 & 35.6 & 11.8 & $.04 *$ \\
\hline 20 & 0 & $\mathrm{G}$ & 27.0 & 17.7 & 40.0 & 14.2 & $<.0001 *$ \\
\hline 22 & -2 & $\mathrm{~B}$ & 16.5 & 10.4 & 27.5 & 11.3 & $.0005^{*}$ \\
\hline 24 & -3 & $\mathrm{~B}$ & 20.4 & 9.2 & 37.8 & 14.8 & $<.0001 *$ \\
\hline 25 & -2 & $\mathrm{~B}$ & 19.3 & 14.6 & 46.6 & 13.7 & $<.0001^{*}$ \\
\hline 27 & 8 & $\mathrm{R}$ & 30.0 & 15.1 & 37.0 & 13.5 & $.01 *$ \\
\hline 28 & 0 & $\mathrm{G}$ & 26.5 & 16.2 & 38.1 & 12.8 & $.002 *$ \\
\hline 30 & 0 & $\mathrm{G}$ & 28.3 & 14.9 & 47.2 & 11.0 & $<.0001^{*}$ \\
\hline
\end{tabular}


Figure 15: Smiling and repose mean ranked VAS score.

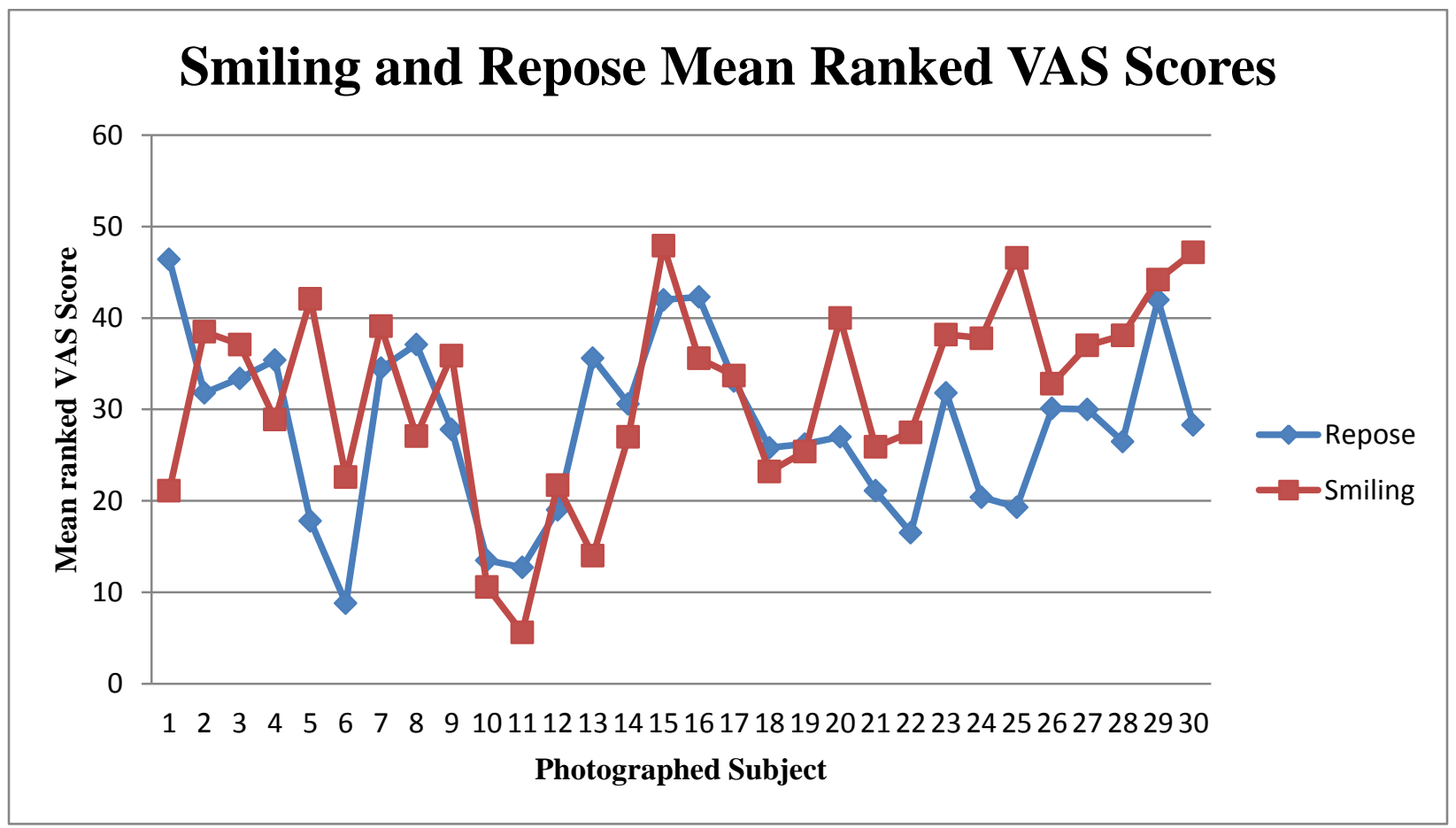

\section{JUDGED ATTRACTIVENESS COMPARING ORTHODONTISTS AND NON- ORTHODONTIC PROFESSIONALS}

When comparing the mean smiling VAS score of the orthodontists and non-orthodontic professionals there was no statistically significant difference in 20 out of 30 of the photographed subjects. In 7 of the photographed subjects the smiling profile was rated statistically significantly higher by the non-orthodontic professionals when compared to the orthodontist. Interestingly, all 7 of the subjects were categorized as having a black (retrognathic) maxillary incisor. In 3 of the photographed subjects the smiling profile was rated statistically significantly 
higher by the orthodontist; 2 of the 3 subjects were categorized as having a green (orthognathic) maxillary incisor.

Table 3: Mean smiling VAS scores comparing orthodontists and non-orthodontic professionals.

\begin{tabular}{|l|l|l|r|r|r|r|r|}
\hline Subject & Distance & Category & \multicolumn{2}{|c|}{ Orthodontist } & \multicolumn{2}{|c|}{ Non-orthodontist } & \multirow{2}{*}{ P } \\
\cline { 4 - 8 } & from & & MEAN & SD & MEAN & SD & \\
\hline 1 & 1 & R & 47.83 & 13.97 & 32.95 & 17.42 & $0.02^{*}$ \\
\hline 4 & -11 & B & 39.50 & 11.57 & 53.50 & 15.31 & $0.01^{*}$ \\
\hline 5 & -8 & B & 48.08 & 19.69 & 67.80 & 8.32 & $0.01^{*}$ \\
\hline 6 & -1 & B & 31.17 & 15.52 & 46.85 & 13.04 & $0.005^{*}$ \\
\hline 7 & -13 & B & 45.42 & 21.56 & 66.20 & 11.07 & $0.001^{*}$ \\
\hline 19 & -6 & B & 36.42 & 18.87 & 47.95 & 11.96 & $0.04^{*}$ \\
\hline 20 & 0 & G & 76.42 & 16.97 & 50.65 & 12.23 & $<0.0001^{*}$ \\
\hline 24 & -3 & B & 47.67 & 18.90 & 62.35 & 13.89 & $0.02^{*}$ \\
\hline 29 & -5 & B & 57.17 & 17.11 & 68.65 & 11.99 & $0.03^{*}$ \\
\hline 30 & 0 & G & 73.83 & 15.18 & 62.45 & 11.92 & $0.02^{*}$ \\
\hline
\end{tabular}

Figure 16: Mean smilng VAS scores compaing orthodontists and non-orthodontic professionals.

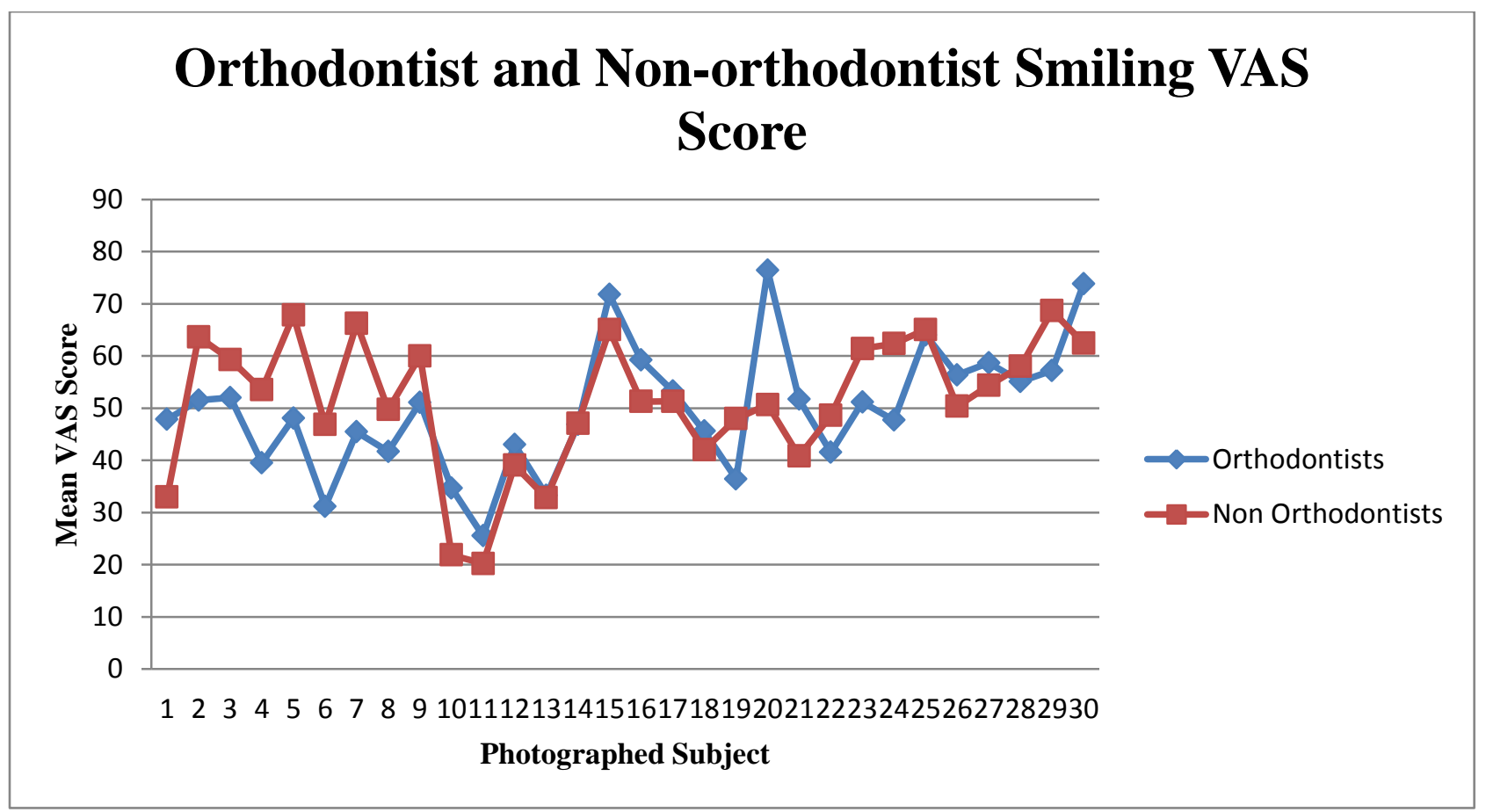




\section{JUDGED ATTRACTIVENESS COMPARING MALES AND FEMALES}

In 26 out of the 30 photographed subjects there was no statistically significant difference in judged attractiveness of smiling profile between males and females. In all 4 photographed subjects in which there was a statistically significant difference between the mean VAS score between males and females the males rated the subjects significantly less attractive than the females rated the photographed subjects. Although not statistically significant, females judged the smiling profile more attractive than males in 22 out of the 30 photographed subjects.

Table 4: Mean smilingVAS scores comparing males and females.

\begin{tabular}{|c|c|c|c|c|c|c|c|}
\hline \multirow[t]{2}{*}{ Subject } & \multirow{2}{*}{$\begin{array}{l}\text { Distance } \\
\text { from } \\
\mathrm{GV}\end{array}$} & \multirow[t]{2}{*}{ Category } & \multicolumn{2}{|l|}{ Male } & \multicolumn{2}{|l|}{ Female } & \multirow[b]{2}{*}{$\mathrm{P}$} \\
\hline & & & MEAN & SD & MEAN & SD & \\
\hline 9 & -7 & B & 49.75 & 15.19 & 63.56 & 13.06 & $0.01 *$ \\
\hline 23 & -11 & B & 49.31 & 13.03 & 65.81 & 11.55 & $0.0007^{*}$ \\
\hline 24 & -3 & B & 49.88 & 18.12 & 63.81 & 13.50 & $0.02 *$ \\
\hline 28 & 0 & G & 50.56 & 15.47 & 63.25 & 14.69 & $0.02 *$ \\
\hline
\end{tabular}


Figure 17: Mean smiling VAS scores comparing males and females.

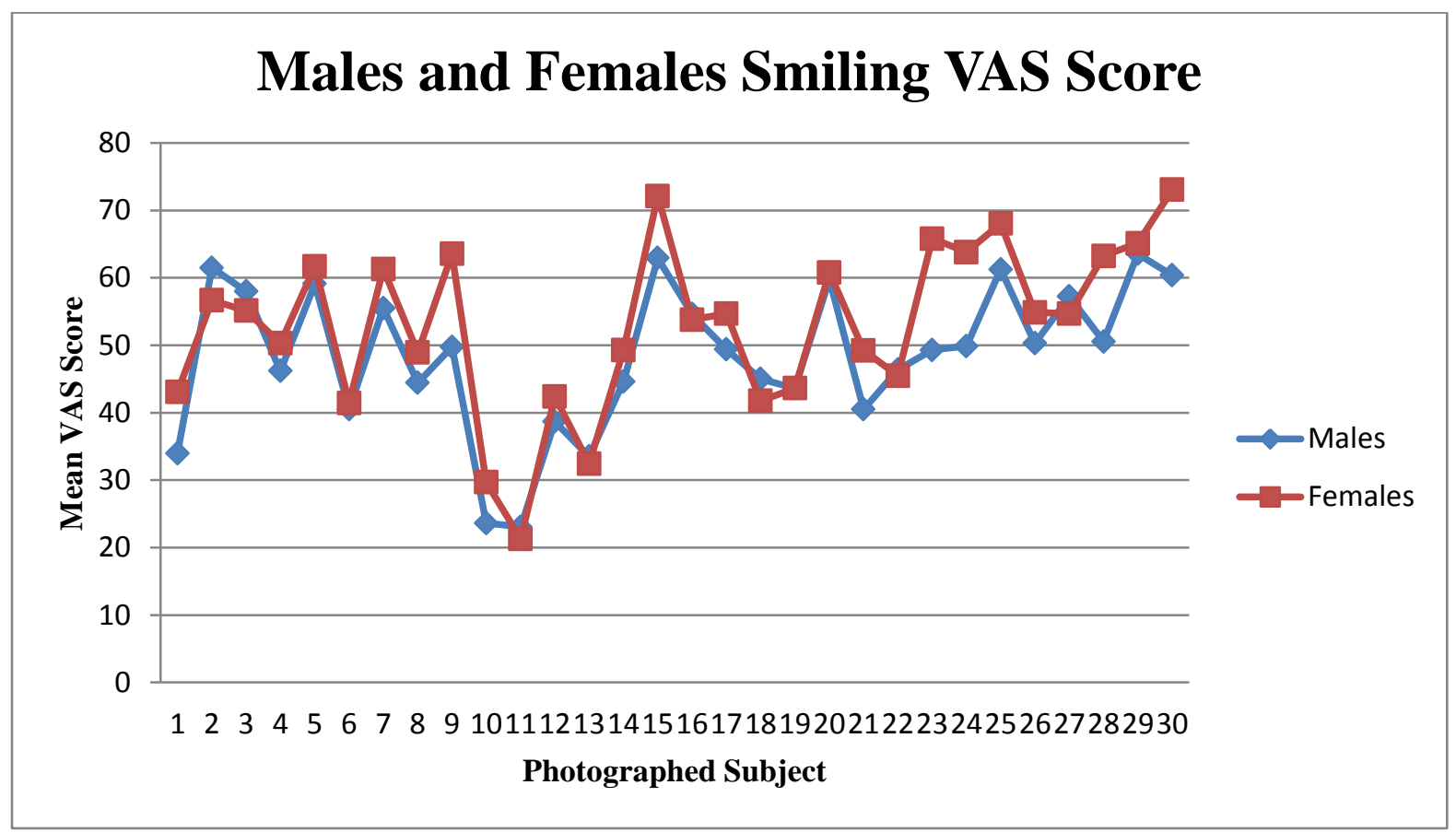

Table 5: Multiple comparison for orthodontists and non-orthodontists and profile view.

\begin{tabular}{|l|l|l|l|l|l|l|l|}
\hline \multicolumn{4}{|l|}{ Orthodontists } & \multicolumn{4}{l|}{ Non-Orthodontists } \\
\hline \multicolumn{2}{|l|}{ Repose } & \multicolumn{3}{l|}{ Smile } & \multicolumn{2}{l|}{ Repose } & \multicolumn{2}{l|}{ Smile } \\
\hline LS & Std & LS & Std & LS & Std & LS & Std \\
MEAN & Err & MEAN & Err & MEAN & Err & MEAN & Err \\
\hline $31.2^{\text {ac }}$ & 1.6 & $28.8^{\text {ad }}$ & 1.6 & $26.4^{\text {bc }}$ & 1.5 & $33.5^{\text {bd }}$ & 1.5 \\
\hline
\end{tabular}

Significant p-value for multiple comparison of sex* view interaction

${ }^{a}$ Repose vs. smile for orthodontists.

${ }^{\mathrm{b}}$ Repose vs. smile for non-orthodontists

${ }^{c}$ Orthodontists vs. non-orthodontists for repose

${ }^{\mathrm{d}}$ Orthodontists vs. non-orthodontists for smile

Orthodontists as a group judged the repose profile statistically significantly higher than the smiling profile, while non-orthodontists as a group judged the smiling profile statistically significantly higher than the repose profile. Additionally, orthodontists judged the repose profile significantly higher than the non-orthodontists judged the repose profile. Non-orthodontists 
judged the smiling profile significantly higher than orthodontists judged the smiling profile (See Table 5 above).

JUDGEMENT OF SMILING PROFILE RELATIVE TO AP INCISOR POSITION

Figure 18: Mean Smiling VAS Score and AP Maxillary Incisor Postion.

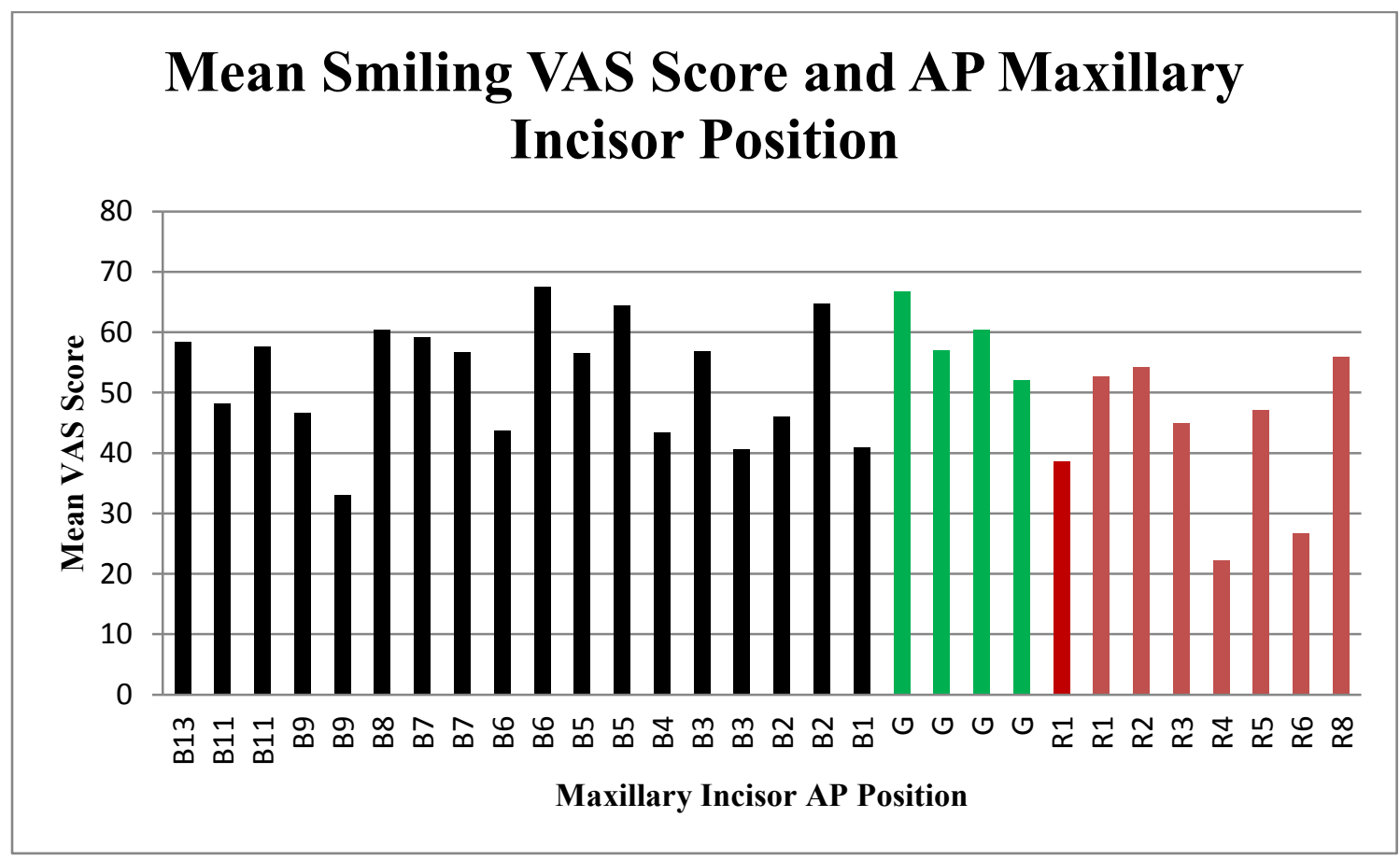

Table 6: Multiple comparisons for orthodontists and non-orthodontists and maxillary incisor AP position.

\begin{tabular}{|l|l|l|l|l|l|l|l|l|l|l|l|}
\hline \multicolumn{4}{|l|}{ Orthodontists } & \multicolumn{4}{l|}{ Non-orthodontists } \\
\hline Black & \multicolumn{1}{l|}{ Green } & \multicolumn{1}{l|}{ Red } & Black & Green & Red \\
\hline LS & Std & LS & Std & LS & Std & LS & Std & LS & Std & LS & Std \\
MEAN & Err & MEAN & Err & MEAN & Err & MEAN & Err & MEAN & Err & MEAN & Err \\
\hline $26.1^{\text {af }}$ & 2.6 & $42.4^{\text {ab }}$ & 5.2 & $28.1^{\text {be }}$ & 3.7 & $37.5^{\text {df }}$ & 2.4 & $38.1^{\text {c }}$ & 5.0 & $22.2^{\text {cde }}$ & 3.6 \\
\hline
\end{tabular}

Significant p-value for multiple comparison of panel*GVP

${ }^{a}$ Black vs. Green GV position for orthodontists.

${ }^{\mathrm{b}}$ Red vs. Green GV position for orthodontists.

${ }^{c}$ Red vs. Green GV position for non-orthodontists.

${ }^{\mathrm{d}}$ Red vs. Black GV position for non-orthodontists.

${ }^{\mathrm{e}}$ Orthodontist vs non-orthodontists for Red GV position

${ }^{\mathrm{f}}$ Orthodontist vs non-orthodontists for Black GV position 
Orthodontists judged the subjects with category green maxillary incisors statistically significantly higher than the subjects with category red and category black maxillary incisors. There is no statistically significant difference between the orthodontists' judgement of the subjects with category black and category red maxillary incisors. Non-orthodontists judged the subjects with category red maxillary incisors statistically significantly less than the subjects with category black and category green maxillary incisors. However, there was no significant difference between the non-orthodontists' judgement of the subjects with category black and category green maxillary incisors.

\section{AP MAXILLARY INCISOR POSITION AND RATERS OPINION OF THE AP MAXILLARY}

\section{INCISOR POSITION}

Table 7: Contingency table of AP maxillary incisor category and raters opinion of maxillary incisor position.

\begin{tabular}{|l|l|l|l|l|}
\hline Category & $\begin{array}{l}\text { Stay the } \\
\text { same } \\
(\%)\end{array}$ & $\begin{array}{l}\text { Move forward } \\
(\%)\end{array}$ & $\begin{array}{l}\text { Move } \\
\text { backward } \\
(\%)\end{array}$ & $\mathrm{p}$ \\
\hline Black & 49.3 & 44.4 & 6.3 & $<0.0001$ \\
\hline Green & 68.0 & 26.6 & 5.5 & \\
\hline Red & 43.1 & 15.3 & 41.6 & \\
\hline
\end{tabular}

When comparing the AP position of the maxillary incisors and the judges' opinion of the maxillary incisor position the judges as whole (orthodontists and non-orthodontists) preferred the category black maxillary incisors stay in the same position $49.3 \%$ of the time and move forward $44.4 \%$ of the time. Regarding the category green maxillary incisors, the judges as a whole preferred the position of the maxillary incisors be maintained $68.0 \%$ of the time. The judges as a 
whole preferred the category red maxillary incisors stay in the same position $43.1 \%$ of the time and move backwards $41.6 \%$ of the time.

Table 8: Contingency table of AP maxillary incisor category and orthodontists and non-orthodontists opinions of maxillary incisor position.

\begin{tabular}{|l|l|l|l|l|l|l|l|l|}
\hline \multirow{2}{*}{ Category } & \multicolumn{3}{|l|}{ Orthodontists } & P & \multicolumn{3}{|l|}{ Non-orthodontists } & \multirow{2}{*}{ P } \\
\cline { 2 - 5 } \cline { 5 - 7 } & Same & Forward & Backward & & Same & Forward & Backward & \\
\hline Black & 32.9 & 65.7 & 1.4 & $<0.0001$ & 59.2 & 31.7 & 9.2 & $<0.0001$ \\
\hline Green & 79.2 & 18.8 & 2.1 & & 61.3 & 31.3 & 7.5 & \\
\hline Red & 53.1 & 5.2 & 41.7 & & 37.1 & 21.4 & 41.5 & \\
\hline
\end{tabular}

When comparing the opinions of the AP maxillary incisor position of orthodontists and nonorthodontists, orthodontists preferred that category black incisors move forward $65.7 \%$ of the time while the non-orthodontists preferred that the category black incisors stay in the same position $59.2 \%$ of the time. Both groups agreed that they would like the category green incisors to stay in the same position the majority of the time. When evaluating category red incisors the orthodontists preferred the same position of the incisors $53.1 \%$ of the time and preferred that the incisors move backwards in $41.7 \%$ of the time. Non-orthodontist preferred the category red incisors stay in the same position $37.1 \%$ of the time, move forward $21.4 \%$ of the time, and move backwards $41.5 \%$ of the time. 


\section{CHAPTER 5: DISCUSSION}

\section{DATA COLLECTION AND SAMPLE ANALYSIS}

The study was limited to photographed subjects that were between 18-30 years of age. This was to have a sample population that was non-growing and in an effort to limit the effects of natural aging on the profile and facial esthetics. While recruiting subjects to be photographed, it became obvious that the majority of subjects in this specific sample population have maxillary incisors that are positioned posterior to Glabella Vertical. According to the Six Elements Orthodontic Philosophy these subjects would be identified as having a black (retrognathic) maxilla. ${ }^{30}$

\section{PERCIEVED ATTRACTIVENESS OF REPOSE AND SMILING PROFILES}

The current study aimed to analyze the difference in judged attractiveness of smiling and repose profiles of Caucasian females. The raters were shown the subjects' smiling and repose profile images in random order and instructed to rate the attractiveness of the profiles, paying particular attention to the mouth. Each subject was analyzed independently and in half of the subjects there was a significant difference in the perceived attractiveness of the repose and smiling profiles. The subjects that had smiling profiles that were rated significantly lower than their repose profiles had prognathic (category red) incisors or severely retrognathic (category black) incisors. Although not statistically significant, 18 of the 30 subjects had smiling profiles that were judged more attractive than their repose profiles. When studying facial attractiveness, Tatarunaite and colleagues found that a smiling facial appearance makes a woman look more attractive. ${ }^{52}$ Interestingly, Tatarunaite also found that smiling that does not significantly affect the facial attractiveness of men. ${ }^{52}$ When comparing the mean ranking scores of the repose and smiling profiles orthodontists judged the smiling profiles significantly lower than non-orthodontists 
judged the smiling profiles. Previous studies have provided conflicting results as to whether orthodontists are more sensitive than laypersons in their judgement of facial attractiveness. ${ }^{10,19 \text {, }}$ 20,42 Interestingly, in the current study orthodontists appear to be more critical of the smiling profile, while non-orthodontists frequently prefer the smiling profile over the repose profile. Although not statistically significant, the majority of females rated the smiling profiles higher than males rated the smiling profiles. These results could suggest that males are potentially more critical of the facial attractiveness of females.

This study reinforces the opinions of Andrews, Sarver, Ackerman, and Cao that it is important for the orthodontist to extensively evaluate both the repose and smiling profile during diagnosis and treatment planning. ${ }^{2,3,5,30,31}$ For example, a patient might have a very attractive repose soft tissue profile according to multiple conventional soft tissue analyses, however the patient's appearance from a lateral smiling perspective might be dramatically different. It has been previously determined that soft tissue structures do not reliably convey the positions of the underlying hard tissue structures. ${ }^{1,27}$ The varying attractiveness of the smiling profile of a patient might affect the orthodontist's ultimate treatment plan especially with regards to determining whether to alter the AP position of the maxillary incisors through retraction or proclination. From this research it can be suggested that standard orthodontic records should include frontal repose, frontal smiling, profile repose, and profile smiling images to be able to obtain a more comprehensive diagnosis.

\section{ESTHETICALLY OPTIMAL AP INCISOR POSITION}

This study was also looking to identify if there is an agreed upon esthetically optimal AP position of the maxillary incisors in Caucasian females. Orthodontists found the subjects with 
category green maxillary incisors to be rated significantly more attractive than the subjects with category black or red maxillary incisors. Interestingly, the non-orthodontists rated the attractiveness of category black and category green incisors very similarly. Non-orthodontists found the subjects with prognathic (category red) incisors had the least attractive smiling profiles. These results differ from the results of previous studies by Schlosser and Cao in which they found that protusion of the upper anterior teeth was more attractive than retrusion of the upper anterior teeth. ${ }^{31,34}$ However, the orthodontists in the current study rated the category red incisors slightly more attractive than category black incisors. These results suggest that orthodontists slightly prefer the appearance of a protruded maxillary incisor over the appearance of a retruded maxillary incisor, while non-orthodontists significantly prefer the appearance of a retruded maxillary incisor over the appearance of a protruded maxillary incisor.

When raters were shown the subjects with category green incisors a strong majority $(68 \%)$ of the raters liked the AP position of the incisor and preferred the incisor stay in the current AP position. These results support the findings of Will Andrews that the forehead is a useful landmark for assessing the facial profile for adult white females as it relates to the AP maxillary incisor position. ${ }^{1}$ When non-orthodontists were shown subjects with category black incisors they liked the AP position of the incisor the majority (59.2\%) of the time and did not want the maxillary incisor to move forward. Non-orthodontists appear to find retruded maxillary incisors more attractive than orthodontist find retruded maxillary incisors. These results demonstrate that there is a significant difference in the perceived attractiveness of the AP position of the maxillary incisor between orthodontists and non-orthodontist.

Previous studies that evaluated the AP position of the maxillary incisors used one photographed subject and digitally altered the AP incisor position. ${ }^{31,34}$ However, this study included multiple 
photographed subjects with a variety of AP incisor positions and facial profiles. Additionally, Cao's study included an Asian female, which might have some effect on the difference in opinion of the esthetically optimal AP position of the maxillary incisor. ${ }^{31}$ This study only examined Caucasian females. It should be recognized that these results might not be pertinent when evaluating various ethnicities and genders. Ethnic and racial differences play a major role in diversifying esthetic preferences. ${ }^{11}$

A potential limitation of the study that must be addressed is when asking raters to judge the attractiveness of the profiles of photographed subjects while paying particular attention to the mouth; it becomes obvious that there are many other facial features that might affect the raters' opinion of facial attractiveness. The subject with the highest rated facial attractiveness from a lateral smiling prospective had maxillary incisors position $6 \mathrm{~mm}$ posterior to Glabella Vertical (B6). It is important to recognize that research has revealed that facial attractiveness does not depend on any single feature. ${ }^{52}$ The rater's judgement might have been influenced by multiple confounding variables such as the subject's hair, complexion, make up, the size and contour of the nose and chin. While interpreting the results of this study it is important to acknowledge that it could have been a difficult task for the raters to judge facial attractiveness while focusing specifically on the mouth.

Utilizing the facial plane Glabella Vertical appears to be a relatively straightforward and effective method for evaluating and quantifying the AP position of maxillary incisors. ${ }^{6}$ Positioning a patient in adjusted natural head posture and capturing a photograph with the vertical line and the millimeter ruler can be easily incorporated into an orthodontist's treatment planning process. This process could be especially useful for determining the optimal AP position of the maxilla during orthognathic surgical treatment planning. 


\section{NULL HYPOTHESIS TESTING.}

1. REJECTED: There was a significant difference in the judged attractiveness of photographed subjects based on their smiling profiles versus their repose profiles.

2. REJECTED: Orthodontists judged subjects with category green incisors most attractive. Non-orthodontists judged subject with category green and category black incisors most attractive.

\section{CLINICAL IMPLICATIONS}

It is well known that one of the motivating factors for a patient to undergo orthodontic treatment is to improve his or her dental esthetics while enhancing his or her dentofacial appearance. ${ }^{13-15}$ In order for the orthodontist to completely address the patient's dentofacial appearance the orthodontist must thoroughly evaluate the patient from multiple perspectives. This research suggests including a smiling profile image as part of every patient's initial records. Using Glabella Vertical as a frontal facial plane is a relatively simple and straightforward method to assess the AP position of the maxillary incisors. Non-orthodontists find prognathic maxillary incisors least attractive. This might influence an orthodontist to extract on a patient that has prognathic maxillary incisors prior to orthodontic treatment. Additionally, non-orthodontists had no significant preference in facial attractiveness between the category green (orthognathic) and category black (retrognathic) maxillary incisors. Orthodontists appear to be more unforgiving of the appearance of retruded maxillary incisors. Regardless, the AP position of the maxillary incisors can have a clinically significant effect on the perceived attractiveness of a patient from a smiling lateral perspective. 


\section{CHAPTER 6: SUMMARY AND CONCLUSIONS}

\section{SUMMARY}

The aim of this study was to determine if there is a difference in the judged attractiveness of the smiling and repose profiles in Caucasian females and to identify if there is an esthetically optimal AP position if the maxillary incisors in Caucasian females. Orthodontists and nonorthodontists rated the attractiveness of the repose and smiling profile of 30 randomly selected Caucasian females 18-30 years old. Statistical analyses were performed for the variables for each photographed subject, with multiple subjects displaying statistical significance.

\section{CONCLUSIONS}

Based on the results of this study, the following conclusions have been reached:

1. In some Caucasian females there is a significant difference in the perceived attractiveness when comparing repose and smiling profiles.

2. All patients should be evaluated from a smiling lateral prospective during orthodontic treatment planning.

3. Orthodontists rate maxillary incisors that lie on Glabella Vertical to be significantly more attractive than maxillary incisors that lie anterior or posterior to Glabella Vertical.

4. Non-orthodontists rate maxillary incisors that lie on Glabella Vertical or that lie posterior to Glabella Vertical more attractive than maxillary incisors that are positioned anterior to Glabella Vertical.

5. Non-orthodontists appear to be more tolerant of retruded maxillary incisors from a lateral smiling perspective in Caucasian females. 


\section{CHAPTER 7: RECOMMENDATIONS FOR FUTURE RESEARCH}

\section{RECOMMENDATIONS ON SAMPLE COLLECTION}

The current study could be enhanced by collecting a sample of photographs in which the AP position of the maxillary incisor is more evenly distributed. For example, a sample with 10 subjects with category black (retrognathic) incisors, 10 subjects with category green (orthognathic) incisors, and 10 subjects with category red (prognathic) incisors would be beneficial and enhance the statisticial analysis and relability of the results of the study. It would be valuable to repeat the study increasing the number of raters to judge the photographs. Additionaly, including a larger proportion of orthodontists that are not trained in regularly evaluating the the smiling profile could potentially have a significant effect on the results of the study. This study aimed to specifically evaluate Caucasian females however, the study should be continued to include and compare various genders and ethnicities to see if there is a difference in perceived attractiveness of the AP position of the maxillary incisor.

\section{RECOMMENDATIONS OF METHODOLOGY}

This research would significantly benefit from developing a method to better limit the effects of confounding variables such as hair, complexion, make up, nose, chin, and other facial features on the raters' perception of attractiveness. Ensuring that the raters are only focusing on the position of the upper front teeth is one of the difficulties of the current study. Repeating the study by digitally changing the AP position of the maxillary incisors of the photographed subjects might alleviate some of the confounding variables. It would also be advantageous to study how the size and shape of the nose affects the perceived attractiveness of the AP position of the maxillary incisor. 


\section{REFERENCES}

1. Andrews WA. AP Relationship of the maxillary central incisors to the forehead in adult white females. Angle Orthodontist. 2006;78(4):662-669.

2. Sarver DM, Ackerman MB. Dynamic smile visualization and quantification: Part 1. Evolution of the concept and dynamic records for smile capture. American Journal of Orthodontics \& Dentofacial Orthopedics. 2003;124(1):4-12.

3. Sarver DM, Ackerman MB. Dynamic smile visualization and quantification: Part 2. Smile analysis and treatment strategies. American Journal of Orthodontics \& Dentofacial Orthopedics. 2003;124(2):116-127.

4. Janzen EK. A balanced smile - A most important treatment objective. American Journal of Orthodontics \& Dentofacial Orthopedics. 1977;72(4):359-372.

5. Andrews LF AW. Syllabus of the Andrews orthodontic philosophy. U.S, 2001(Ninth ed).

6. Tomblyn J. Facial Planes as Landmarks for Diagnosis and Treatment Planning. WVU Master Thesis. 2015.

7. Posnick JC. 2014. Orthognathic Surgery: Principles \& Practice. Volume 1. Elsevier, 2014.

8. Arnett GW, Bergman T. Facial Keys to orthodontic diagnosis and treatment planning: Part 1. American Journal of Orthodontics \& Dentofacial Orthopedics. 1993;103(4):299312.

9. Arnett GW, Bergman T. Facial Keys to orthodontic diagnosis and treatment planning: Part 2. American Journal of Orthodontics \& Dentofacial Orthopedics. 1993;103(3):395411.

10. Phillips C, Tulloch C, Dann C. Rating of facial attractiveness. Community Den Oral Epidemiol. 1992;20:213-220.

11. Turkkahraman H, Gokalp H. Facial profile preferences among various layers of Turkish population. Angle Orthodontist. 2004;74(5):640-647.

12. Herson LE, Giddon DB. Determinants of facial profile self-perception. American Journal of Orthodontics. 1980;78(3):279-295. 
13. Wedrychowska-Szulc B, Syrynska M. Patient and parent motivation of orthodontic treatment - a questionnaire study. European Journal of Orthodontics. 2010;32:447-452.

14. Kilpelainen P, Phillips C, Tulloch J. Anterior tooth position and motivation for early treatment. Angle Orthodontist. 1993;63(3):171-174.

15. Bos A, Hoogstaten J, Prahl-Andersen B. Expectations of treatment and satisfaction with dentofacial appearance in orthodontic patients. American Journal of Orthodontics \& Dentofacial Orthopedics. 2003;123(2):127-132.

16. Farkas LG, Sohm P, Kolar JC, Katic BA, Munro IR. Inclinations of the Facial Profile: Art versus reality. Plastic and Reconstructive Surgery. 1985;75(4):509-519.

17. Isiksal E, Hazar S, Akyalcin S. Smile esthetics: Perception and comparison of treated and untreated smiles. American Journal of Orthodontics \& Dentofacial Orthopedics. 2006;129(1):8-16.

18. Kamashita Y, Kamada Y, Kawahata N, Nagaoka E. Influence of lip support on the softtissue profile of complete denture wearers. Journal of Oral Rehabilitation. 2006;33:102109.

19. Peck H, Peck S. A concept of facial esthetics. Angle Orthodontist. 1970;40(4):284-318.

20. Spyropoulos MN, Halazonetis DJ. Significance of the soft tissue profile on facial esthetics. American Journal of Orthodontics \& Dentofacial Orthopedics. 2001;119(5):464-471.

21. Czarnecki ST, Nanda RS, Currier GF. Perceptions of a balanced facial profile. American Journal of Orthodontics \& Dentofacial Orthopedics. 1993;104(2):180-187.

22. Proffit, WR, Fields HW. Contemporary Orthodontics. Mosby, 2000;255.

23. Ricketts RM. Cephalometric analysis and synthesis. Angle Orthodontist. 1961;31(3):141156.

24. Steiner C. The use of cephalometrics as an aid to planning and assessing orthodontic treatment. American Journal of Orthodontics. 1960;46(10):721-735.

25. Holdaway R. A soft-tissue cephalometric analysis and its use in orthodontic treatment planning. Part 1. American Journal of Orthodontists. 1963;84(1):1-28. 
26. Devereux L, Moles D, Cunningham J, McKnight M. How important are lateral cephalometric radiographs in orthodontic treatment planning? American Journal of Orthodontics \& Dentofacial Orthopedics. 2011;139(2):175-181.

27. Fields HW, Vann WF, Vig KW. Reliability of soft tissue profile analysis in children. The Angle Orthodontist. 1982;52(2):159-165.

28. Masoud MI. Anecdote, Expertise and Evidence: Applying New Knowledge to Everyday Orthodontics. Department of Orthodontics and Pediatric Dentistry and Center for Human Growth and Development The University of Michigan, 2017;263-286.

29. Andrews LF. Straight Wire: the concept and appliance. Third Printing, 2003.

30. Andrews LF. The Six Elements of Orofacial Harmony. The Andrews Journal of Orthodontics and Orofacial Harmony. 2000;1(1):i-iii.

31. Cao L, Zhang K, Bai D, Jing Y, Tian Y, Guo Y. Effect of maxillary incisor inclination and anteroposterior position on smiling profile esthetics. Angle Orthodontist. 2011;81(1):121129.

32. Tremont T. Art, Science, and The Six Elements of Orofacial Harmony. The Andrews Journal of Orthodontics and Orofacial Harmony. 2000;1(1):36-38.

33. Ghaleb N, Bouserhal J, Bassil-Nassif N. Aesthetic evaluation of profile incisor inclination. European Journal of Orthodontics. 2011;33:228-235.

34. Schlosser JB, Preston CB, Lampasso J. The effects of computer-aided anterior posterior maxillary incisor movement on ratings of facial attractiveness. American Journal of Orthodontics \& Dentofacial Orthopedics. 2005;127:1:17-24.

35. Ellis HS. The effects of computer-aided anterioposterior forehead movement on ratings of facial attractiveness. Journal of Dental and Oral Health. 2017;3(5):77.

36. Barbera AL, Sampson WJ, Townsend GC. An evaluation of head position and craniofacial reference line variation. Journal of Comparative Human Biology. 2009;60:128.

37. Moorees CP, Kean MR. Natural head position, a basic consideration in the interpretation of cephalometric radiographs. Am J Phys Anthropol. 1958;16(2):213-234. 
38. Peng L, Cook MS. Fifteen-year reproducibility of natural head posture: A longitudinal study. . American Journal of Orthodontics \& Dentofacial Orthopedics. 1999;116(1):8285.

39. Cooke MS. Five-year reproducibility of natural head posture: A longitudinal study. . American Journal of Orthodontics \& Dentofacial Orthopedics. 1990;97(6):489-494.

40. Phillips C, Tulloch C, Dann C. Rating of facial attractiveness. Community Den Oral Epidemiol. 1992;20:213-220.

41. Oliveria PLE, Motta AFJ, Guerra CJ, Mucha JN. Comparison of two scales for evaluation of smile and dental attractiveness. Dental Press Journal of Orthodontics. 2015;20(2):4248.

42. Knight H, Keith O. Ranking facial attractiveness. European Journal of Orthodontics. 2005;27:340-348.

43. Kirschneck C, Proff P, Reicheneder C, Lippold. Short-term effects of systematic premolar extraction on lip profile, vertical dimension and cephalometric parameters in borderline patients for extraction therapy - a retrospective cohort study. Clin Oral Invest. 2016;20:865-874.

44. Bowman SJ, Johnston LE. The esthetic impact of extraction and nonextraction treatments on Caucasian patients. Angle Orthodontist. 2000;70(1):3-10.

45. Stephens CK, Boley JC, Behrents RG, Alexander RG, Buschang PH. Long-term profile changes in extraction and nonextraction patients. American Journal of Orthodontics and Dentofacial Orthopedics. 2005;128(4):450-457.

46. Abu Arqoub SH, Al-Khateeb SN. Preception of facial profile attractiveness of different antero-posterior and vertical proportions. European Journal of Orthodontics. 2011;33:103-111.

47. Cochrane SM, Cunningham SJ, Hunt NP. A comparison of the perception of the facial profile between general public and three groups of clinicians. International Journal of Adult Orthodontics and Orthognathic Surgery. 1999;14:291-295.

48. Hall D, Taylor RW, Jacobson A, Sadowsky PL, Bartolucci A. The perception of optimal profile in African Americans versus white Americans as assessed by orthodontist and the lay public. American Journal of Orthodontics and Dentofacial Orthopedics. 2000;118(5):514-525. 
49. Sutter RE, Turley PK. Soft tissue evaluation of contemporary Caucasian and African American female facial profiles. Angle Orthodontist. 1998;68(6):487-496.

50. Cala L, Spalj S, Slaj M, Lapter MV, Slaj M. Facial profile preferences: Differences in the perception of children with and without orthodontic history. American Journal of Orthodontics and Dentofacial Orthopedics. 2010;138(4):442-450.

51. Borman H, Ozgur F, Gursu G. Evaluation of soft-tissue morphology of the face in 1,050 young adults. Annuals of Plastic Surgery. 1999;42(3):280-288.

52. Tatarunaite E, Playle R, Hood K, Shaw W, Richmond S. Facial attractiveness: A longitudinal study. American Journal of Orthodontics and Dentofacial Orthopedics. 2005;127(6):676-682. 
Action Date

To

From

Approval Date

Expiration Date

Subject

Protocol Number

Title
07/10/2017

Timothy Tremont

WVU Office of Research Integrity and Compliance

$07 / 10 / 2017$

$07 / 09 / 2018$

Protocol Approval Letter

1705573264

Identifying the Esthetically Optimal Anterior-Posterior Position of Maxillary Incisors in Caucasian Females

The above-referenced research study was reviewed by the West Virginia University Institutional Review Board IRB and was approved in accordance with 46 CFR 46.101b.

It has been determined that this study is of minimal risk and meets the criteria as defined by the expedited categories listed below:

- The questionnaire states the images will be shown to dental students, and orthodontic faculty/ residents The consent form states the images will be shown to auxiliary staff, orthodontic faculty and orthodontic residents Please make the correction to the consent form.

- Please clarify how you will be de-identifying the photos, i.e. assigning number/code.

- ICFs: Contact Persons- Please provide 24/7 number

Documents reviewed and/or approved as part of this submission:

Only Minimal Risk Consent Form With HIPAA REVISED.pdf: 2017-07-06-04:00

Visual Analogue Scale - Survey.docx: 2017-07-03-04;00

Only Minimal Risk Consent Form Without HIPAA.pdf: 2017-06-29-04:00

Protocol Narrative REVISED.docx: 2017-07-06-04:00 
Documents for use in this study are available in the WVUkc system in the Notes and Attachments section of your protocol.

The Office of Research Integrity and Compliance is here to provide assistance to you from the initial submission of an IRB protocol and all subsequent activity. Please feel free to contact us by phone at 304.293.7073 with any question you may have. Thank you.

WVU Office of Research Integrity and Compliance

Date:07/10/2017

Signed:



Lilo Ast

Senior Program Coordinator

Once you begin your human subject research, the following regulations apply:

1. Unanticipated or serious adverse events/side effects encountered in this research study must be reported to the IRB within five (5) days via the Notify IRB action.

2. Any modifications to the study protocol or informed consent form must be reviewed and approved by the IRB prior to implementation via submission of an amendment.

3. You may not use a modified informed consent form until it has been approved and validated by the IRB. 


\section{APPENDIX B - RAW STATISTICS}

Means of ranking scores of view by patient

\begin{tabular}{|c|c|c|c|c|c|c|c|}
\hline \multirow[t]{2}{*}{ Patient } & \multirow[t]{2}{*}{$\mathrm{GV}$} & \multirow[t]{2}{*}{ position } & \multicolumn{2}{|c|}{ REPOSE } & \multicolumn{2}{|l|}{ SMILE } & \multirow[t]{2}{*}{ p-value* } \\
\hline & & & MEAN & SD & MEAN & SD & \\
\hline 1 & 1 & $\mathrm{R}$ & 46.4 & 13.6 & 21.1 & 14.9 & $<<.0001$ \\
\hline 2 & -7 & $\mathrm{~B}$ & 31.8 & 17.3 & 38.5 & 18.7 & .17 \\
\hline 3 & -5 & B & 33.4 & 14.9 & 37.1 & 15.5 & .35 \\
\hline 4 & -11 & $\mathrm{~B}$ & 35.4 & 16.7 & 28.9 & 16.1 & .15 \\
\hline 5 & -8 & $\mathrm{~B}$ & 17.8 & 13.6 & 42.1 & 14.6 & $<.0001$ \\
\hline 6 & -1 & $\mathrm{~B}$ & 8.8 & 7.1 & 22.6 & 13.6 & $<.0001$ \\
\hline 7 & -13 & $\mathrm{~B}$ & 34.5 & 16.1 & 39.1 & 17.1 & .23 \\
\hline 8 & -9 & B & 37.1 & 16.1 & 27.1 & 15.7 & 0.03 \\
\hline 9 & -7 & $\mathrm{~B}$ & 27.8 & 14.6 & 35.9 & 13.7 & .05 \\
\hline 10 & 6 & $\mathrm{R}$ & 13.5 & 12.5 & 10.6 & 13.5 & .31 \\
\hline 11 & 4 & $\mathrm{R}$ & 12.7 & 10.0 & 5.6 & 4.4 & $<.0001$ \\
\hline 12 & -3 & B & 19.0 & 13.8 & 21.7 & 15.7 & .45 \\
\hline 13 & -9 & $\mathrm{~B}$ & 35.6 & 15.3 & 14.0 & 14.9 & $<.0001$ \\
\hline 14 & 5 & $\mathrm{R}$ & 30.6 & 12.6 & 27.0 & 14.7 & .35 \\
\hline 15 & -6 & B & 42.0 & 12.7 & 47.9 & 10.4 & .04 \\
\hline 16 & 2 & $\mathrm{R}$ & 42.3 & 15.2 & 35.6 & 11.8 & .04 \\
\hline 17 & 0 & $\mathrm{G}$ & 33.1 & 15.2 & 33.7 & 15.6 & .89 \\
\hline 18 & -4 & $\mathrm{~B}$ & 25.8 & 12.0 & 23.2 & 11.1 & .29 \\
\hline 19 & -6 & $\mathrm{~B}$ & 26.2 & 14.2 & 25.4 & 14.9 & .82 \\
\hline 20 & 0 & $\mathrm{G}$ & 27.0 & 17.7 & 40.0 & 14.2 & $<.0001$ \\
\hline 21 & 3 & $\mathrm{R}$ & 21.1 & 16.9 & 25.9 & 14.9 & .22 \\
\hline 22 & -2 & $\mathrm{~B}$ & 16.5 & 10.4 & 27.5 & 11.3 & .0005 \\
\hline 23 & -11 & B & 31.8 & 13.3 & 38.2 & 14.6 & .08 \\
\hline 24 & -3 & $\mathrm{~B}$ & 20.4 & 9.2 & 37.8 & 14.8 & $<.0001$ \\
\hline 25 & -2 & $\mathrm{~B}$ & 19.3 & 14.6 & 46.6 & 13.7 & $<.0001$ \\
\hline 26 & 1 & $\mathrm{R}$ & 30.1 & 15.8 & 32.8 & 19.7 & .46 \\
\hline 27 & 8 & $\mathrm{R}$ & 30.0 & 15.1 & 37.0 & 13.5 & .01 \\
\hline 28 & 0 & $\mathrm{G}$ & 26.5 & 16.2 & 38.1 & 12.8 & .002 \\
\hline 29 & -5 & $\mathrm{~B}$ & 42.0 & 14.2 & 44.2 & 13.4 & .48 \\
\hline 30 & 0 & $\mathrm{G}$ & 28.3 & 14.9 & 47.2 & 11.0 & $<.0001$ \\
\hline
\end{tabular}

*P-value from paired t-test analysis 
Means of ranking scores of panel by patient

\begin{tabular}{|l|l|l|r|r|r|r|r|}
\hline Patient & \multirow{2}{*}{ GV } & position & \multicolumn{2}{|c|}{ Orthodontist } & \multicolumn{2}{l|}{ Lay-peopel } & p-value* \\
\cline { 3 - 8 } & & & MEAN & SD & MEAN & SD & \\
\hline 1 & 1 & R & 38.71 & 14.42 & 30.78 & 20.92 & 0.11 \\
\hline 2 & -7 & B & 33.25 & 19.54 & 36.25 & 17.52 & 0.53 \\
\hline 3 & -5 & B & 30.83 & 13.87 & 37.88 & 15.48 & 0.07 \\
\hline 4 & -11 & B & 29.42 & 18.12 & 33.75 & 15.64 & 0.32 \\
\hline 5 & -8 & B & 22.08 & 12.81 & 34.63 & 20.07 & 0.003 \\
\hline 6 & -1 & B & 11.08 & 8.80 & 18.48 & 14.11 & 0.01 \\
\hline 7 & -13 & B & 26.08 & 14.80 & 43.23 & 14.27 & $<0.0001$ \\
\hline 8 & -9 & B & 29.38 & 17.72 & 33.70 & 15.82 & 0.32 \\
\hline 9 & -7 & B & 32.83 & 11.47 & 31.28 & 16.32 & 0.68 \\
\hline 10 & 6 & R & 16.04 & 16.20 & 9.65 & 10.16 & 0.09 \\
\hline 11 & 4 & R & 12.13 & 11.27 & 7.35 & 5.62 & 0.06 \\
\hline 12 & -3 & B & 21.92 & 13.85 & 19.40 & 15.29 & 0.51 \\
\hline 13 & -9 & B & 27.50 & 19.79 & 23.23 & 17.79 & 0.38 \\
\hline 14 & 5 & R & 26.75 & 12.34 & 30.03 & 14.53 & 0.36 \\
\hline 15 & -6 & B & 46.67 & 11.49 & 43.90 & 12.20 & 0.37 \\
\hline 16 & 2 & R & 41.92 & 12.34 & 37.15 & 14.63 & 0.19 \\
\hline 17 & 0 & G & 34.25 & 14.53 & 32.90 & 15.83 & 0.73 \\
\hline 18 & -4 & B & 27.75 & 12.24 & 22.53 & 10.81 & 0.08 \\
\hline 19 & -6 & B & 23.42 & 16.24 & 27.23 & 13.24 & 0.31 \\
\hline 20 & 0 & G & 47.50 & 11.37 & 25.05 & 14.44 & $<0.0001$ \\
\hline 21 & 3 & R & 27.96 & 18.81 & 20.83 & 13.62 & 0.08 \\
\hline 22 & -2 & B & 20.88 & 11.59 & 22.68 & 12.52 & 0.57 \\
\hline 23 & -11 & B & 31.96 & 15.07 & 36.78 & 13.51 & 0.19 \\
\hline 24 & -3 & B & 23.54 & 9.89 & 32.45 & 16.59 & 0.009 \\
\hline 25 & -2 & B & 32.92 & 20.17 & 32.93 & 19.61 & 0.99 \\
\hline 26 & 1 & R & 35.25 & 20.23 & 29.20 & 15.95 & 0.19 \\
\hline 27 & 8 & R & 34.25 & 17.52 & 33.08 & 12.82 & 0.76 \\
\hline 28 & 0 & G & 34.42 & 16.49 & 31.00 & 15.14 & 0.40 \\
\hline 29 & -5 & B & 36.13 & 15.51 & 47.28 & 10.70 & 0.004 \\
\hline 30 & 0 & G & 43.96 & 16.58 & 34.03 & 14.70 & 0.02 \\
\hline & & & & & & \\
\hline
\end{tabular}

$* \mathrm{P}$-value from two sample t-test analysis 
Means of ranking scores of sex by patient

\begin{tabular}{|l|l|l|r|r|r|r|r|}
\hline Patient & \multirow{2}{*}{ GV } & position & \multicolumn{2}{|l|}{ Male } & \multicolumn{2}{l|}{ Female } & p-value* \\
\cline { 4 - 8 } & & & MEAN & SD & MEAN & SD & \\
\hline 1 & 1 & R & 34.09 & 21.30 & 33.41 & 16.78 & 0.89 \\
\hline 2 & -7 & B & 38.72 & 18.74 & 31.53 & 17.20 & 0.12 \\
\hline 3 & -5 & B & 36.19 & 15.59 & 34.28 & 14.94 & 0.62 \\
\hline 4 & -11 & B & 32.97 & 16.27 & 31.28 & 17.16 & 0.69 \\
\hline 5 & -8 & B & 31.91 & 18.19 & 27.94 & 19.12 & 0.40 \\
\hline 6 & -1 & B & 17.75 & 13.58 & 13.66 & 11.88 & 0.20 \\
\hline 7 & -13 & B & 38.78 & 16.42 & 34.81 & 16.83 & 0.34 \\
\hline 8 & -9 & B & 32.22 & 18.36 & 31.94 & 14.82 & 0.95 \\
\hline 9 & -7 & B & 27.66 & 16.07 & 36.06 & 11.80 & 0.02 \\
\hline 10 & 6 & R & 10.63 & 11.30 & 13.47 & 14.57 & 0.39 \\
\hline 11 & 4 & R & 10.25 & 9.02 & 8.03 & 7.82 & 0.30 \\
\hline 12 & -3 & B & 18.38 & 14.80 & 22.31 & 14.58 & 0.29 \\
\hline 13 & -9 & B & 26.72 & 18.96 & 22.94 & 18.19 & 0.42 \\
\hline 14 & 5 & R & 26.19 & 12.86 & 31.41 & 14.30 & 0.13 \\
\hline 15 & -6 & B & 42.41 & 11.26 & 47.47 & 12.20 & 0.09 \\
\hline 16 & 2 & R & 37.84 & 13.85 & 40.03 & 14.10 & 0.53 \\
\hline 17 & 0 & G & 32.03 & 15.60 & 34.78 & 15.01 & 0.48 \\
\hline 18 & -4 & B & 25.38 & 12.86 & 23.59 & 10.22 & 0.54 \\
\hline 19 & -6 & B & 26.09 & 15.11 & 25.50 & 13.95 & 0.87 \\
\hline 20 & 0 & G & 35.56 & 17.19 & 31.38 & 17.25 & 0.33 \\
\hline 21 & 3 & R & 19.41 & 15.27 & 27.59 & 15.90 & 0.04 \\
\hline 22 & -2 & B & 25.16 & 12.39 & 18.84 & 11.14 & 0.04 \\
\hline 23 & -11 & B & 33.63 & 12.18 & 36.31 & 16.04 & 0.45 \\
\hline 24 & -3 & B & 26.59 & 14.67 & 31.63 & 15.13 & 0.18 \\
\hline 25 & -2 & B & 34.75 & 19.18 & 31.09 & 20.27 & 0.46 \\
\hline 26 & 1 & R & 32.22 & 16.97 & 30.72 & 18.78 & 0.74 \\
\hline 27 & 8 & R & 36.53 & 12.12 & 30.50 & 16.41 & 0.10 \\
\hline 28 & 0 & G & 28.00 & 15.27 & 36.56 & 14.98 & 0.03 \\
\hline 29 & -5 & B & 43.91 & 14.74 & 42.28 & 12.80 & 0.64 \\
\hline 30 & 0 & G & 36.50 & 14.96 & 39.00 & 17.22 & 0.54 \\
\hline & & & & & & \\
\hline$-v a n$ & & & & & & & \\
\hline
\end{tabular}

*P-value from two sample t-test analysis 
Mixed model analysis of ranking scores by patient. Test of main effects for rater (panel), panel, sex, view, panel $*$ view, sex * view interaction

\begin{tabular}{|c|c|c|c|c|c|c|c|c|c|c|c|c|}
\hline \multirow[b]{2}{*}{ patient } & \multicolumn{2}{|c|}{$\begin{array}{c}\text { View } \\
(\mathrm{DF}=1)\end{array}$} & \multicolumn{2}{|c|}{$\begin{array}{l}\text { Group } \\
(\mathrm{DF}=1)\end{array}$} & \multicolumn{2}{|c|}{$\begin{array}{c}\text { Sex } \\
(\mathrm{DF}=1)\end{array}$} & \multicolumn{2}{|c|}{$\begin{array}{l}\text { Group*view } \\
(\mathrm{DF}=1)\end{array}$} & \multicolumn{2}{|c|}{$\begin{array}{c}\text { Sex*view } \\
(\mathrm{DF}=1)\end{array}$} & \multicolumn{2}{|c|}{ Rater(Group) } \\
\hline & $\mathrm{F}$ & $\mathrm{P}$ & $\mathrm{F}$ & $\mathrm{P}$ & $\mathrm{F}$ & $\mathrm{P}$ & $\mathrm{F}$ & $\mathrm{P}$ & $\mathrm{F}$ & $\mathrm{P}$ & $\mathrm{Z}$ & $\mathrm{P}$ \\
\hline 1 & 34.50 & $<0.0001$ & 7.02 & 0.01 & 0.06 & 0.81 & 1.15 & 0.29 & 0.37 & 0.55 & -1.58 & 0.11 \\
\hline 2 & 0.69 & 0.41 & 0.49 & 0.49 & 2.97 & 0.10 & 6.28 & 0.02 & 0.13 & 0.72 & -0.33 & 0.74 \\
\hline 3 & 0.22 & 0.64 & 3.78 & 0.06 & 0.30 & 0.59 & 3.66 & 0.07 & 0.99 & 0.33 & -0.43 & 0.67 \\
\hline 4 & 6.30 & 0.02 & 1.22 & 0.28 & 0.20 & 0.66 & 12.04 & 0.002 & 0.10 & 0.76 & -0.04 & 0.97 \\
\hline 5 & 82.68 & $<0.0001$ & 12.99 & 0.001 & 1.39 & 0.25 & 22.29 & 0.0001 & 2.82 & 0.10 & 1.86 & 0.06 \\
\hline 6 & 18.61 & 0.0002 & 11.19 & 0.002 & 3.66 & 0.07 & 6.08 & 0.02 & 0.01 & 0.94 & -1.21 & 0.23 \\
\hline 7 & 0.49 & 0.49 & 22.86 & $<0.0001$ & 1.31 & 0.26 & 5.26 & 0.03 & 1.59 & 0.22 & 0.04 & 0.97 \\
\hline 8 & 7.01 & 0.01 & 1.28 & 0.27 & 0.01 & 0.94 & 2.20 & 0.15 & 0.11 & 0.74 & -0.71 & 0.48 \\
\hline 9 & 1.91 & 0.18 & 0.33 & 0.57 & 10.26 & 0.003 & 13.58 & 0.0009 & 0.004 & 0.95 & -1.36 & 0.17 \\
\hline 10 & 0.16 & 0.69 & 3.09 & 0.09 & 0.65 & 0.43 & 7.69 & 0.01 & 0.02 & 0.90 & 1.48 & 0.14 \\
\hline 11 & 25.47 & $<0.0001$ & 4.51 & 0.04 & 1.04 & 0.32 & 1.64 & 0.21 & 0.004 & 0.95 & 1.9 & 0.06 \\
\hline 12 & 0.31 & 0.58 & 0.38 & 0.54 & 1.00 & 0.33 & 0.42 & 0.52 & 0.10 & 0.75 & 0.06 & 0.95 \\
\hline 13 & 59.28 & $<0.0001$ & 0.88 & 0.36 & 0.73 & 0.40 & 3.91 & 0.06 & 1.18 & 0.29 & 1.99 & 0.04 \\
\hline 14 & 0.99 & 0.33 & 1.10 & 0.30 & 2.98 & 0.10 & 0.06 & 0.81 & 2.82 & 0.10 & -1.0 & 0.32 \\
\hline 15 & 2.97 & 0.10 & 0.84 & 0.37 & 3.00 & 0.09 & 1.46 & 0.24 & 0.61 & 0.44 & 0.21 & 0.83 \\
\hline 16 & 4.32 & 0.05 & 1.53 & 0.23 & 0.34 & 0.56 & 0.51 & 0.48 & 6.17 & 0.02 & 1.38 & 0.17 \\
\hline 17 & 0.0001 & 0.99 & 0.13 & 0.72 & 0.57 & 0.46 & 0.32 & 0.58 & 0.09 & 0.77 & -0.76 & 0.45 \\
\hline 18 & 2.60 & 0.12 & 2.37 & 0.13 & 0.29 & 0.59 & 3.13 & 0.09 & 6.19 & 0.02 & 2.01 & 0.04 \\
\hline 19 & 0.71 & 0.41 & 0.87 & 0.36 & 0.02 & 0.88 & 5.74 & 0.02 & 1.05 & 0.31 & 1.18 & 0.24 \\
\hline 20 & 16.96 & 0.0003 & 53.42 & $<0.0001$ & 1.98 & 0.17 & 0.88 & 0.36 & 0.09 & 0.76 & 0.15 & 0.88 \\
\hline 21 & 1.89 & 0.18 & 3.24 & 0.08 & 4.55 & 0.04 & 0.46 & 0.50 & 1.07 & 0.31 & 0.03 & 0.97 \\
\hline 22 & 11.70 & 0.002 & 0.52 & 0.48 & 6.78 & 0.01 & 5.29 & 0.03 & 0.01 & 0.91 & -0.51 & 0.61 \\
\hline 23 & 2.44 & 0.13 & 1.91 & 0.18 & 0.63 & 0.43 & 4.07 & 0.05 & 10.06 & 0.004 & 0.61 & 0.54 \\
\hline 24 & 36.01 & $<0.0001$ & 9.06 & 0.01 & 3.08 & 0.09 & 11.16 & 0.002 & 0.77 & 0.39 & 0.81 & 0.42 \\
\hline 25 & 47.52 & $<0.0001$ & $<0.0001$ & 1.00 & 1.16 & 0.29 & 1.87 & 0.18 & 1.46 & 0.24 & -0.39 & 0.70 \\
\hline 26 & 0.28 & 0.60 & 1.24 & 0.27 & 0.08 & 0.78 & 0.50 & 0.48 & 0.20 & 0.66 & 1.76 & 0.08 \\
\hline 27 & 6.59 & 0.02 & 0.07 & 0.79 & 1.96 & 0.17 & 0.15 & 0.70 & 0.24 & 0.63 & 2.11 & 0.03 \\
\hline 28 & 8.47 & 0.007 & 0.87 & 0.36 & 5.81 & 0.02 & 15.78 & 0.0004 & 0.27 & 0.61 & 1.09 & 0.28 \\
\hline 29 & 0.04 & 0.83 & 9.74 & 0.004 & 0.22 & 0.64 & 4.25 & 0.04 & 0.41 & 0.53 & 1.04 & 0.30 \\
\hline 30 & 73.01 & $<0.0001$ & 6.90 & 0.01 & 0.47 & 0.50 & 2.18 & 0.15 & 10.31 & 0.003 & 2.50 & 0.01 \\
\hline
\end{tabular}


Adjusted multiple comparison of Least Square (LS) means of ranking scores for patients with significant panel $*$ view interaction

\begin{tabular}{|c|c|c|c|c|c|c|c|c|}
\hline & \multicolumn{4}{|c|}{ ORTHODONTIST } & \multicolumn{4}{|c|}{ LAYPEOPLE } \\
\hline \multirow[t]{2}{*}{ Patient } & \multicolumn{2}{|l|}{ REPOSE } & \multicolumn{2}{|l|}{ SMILE } & \multicolumn{2}{|c|}{ REPOSE } & \multicolumn{2}{|l|}{ SMILE } \\
\hline & $\begin{array}{l}\text { LS } \\
\text { MEAN }\end{array}$ & Std Err & LS MEAN & Std Err & $\begin{array}{l}\text { LS } \\
\text { MEAN }\end{array}$ & Std Err & $\begin{array}{l}\text { LS } \\
\text { MEAN }\end{array}$ & Std Err \\
\hline 2 & 37.1 & 5.0 & $29.4^{\mathrm{d}}$ & 5.0 & $28.6^{\mathrm{b}}$ & 3.9 & $43.9^{\text {bd }}$ & 3.9 \\
\hline 4 & $41.3^{\mathrm{a}}$ & 4.4 & $17.6^{\mathrm{ad}}$ & 4.4 & 31.9 & 3.4 & $35.7^{\mathrm{d}}$ & 3.4 \\
\hline 5 & $16.9^{\mathrm{a}}$ & 3.3 & $27.3^{\mathrm{ad}}$ & 3.3 & $18.3^{\mathrm{b}}$ & 2.6 & $51.0^{\mathrm{bd}}$ & 2.6 \\
\hline 6 & 8.5 & 2.8 & $13.7^{\mathrm{d}}$ & 2.8 & $9.0^{\mathrm{b}}$ & 2.2 & $28.0^{\text {bd }}$ & 2.2 \\
\hline 7 & 28.9 & 4.0 & $23.3^{\mathrm{d}}$ & 4.0 & $37.9^{\mathrm{b}}$ & 3.1 & $48.5^{\mathrm{bd}}$ & 3.1 \\
\hline 9 & $36.9^{\mathrm{c}}$ & 3.5 & $28.8^{\mathrm{d}}$ & 3.5 & $22.3^{\mathrm{bc}}$ & 2.7 & $40.3^{\mathrm{bd}}$ & 2.7 \\
\hline 10 & 12.8 & 3.6 & $19.3^{\mathrm{d}}$ & 3.6 & $14.0^{\mathrm{b}}$ & 2.8 & $5.4^{\mathrm{bd}}$ & 2.8 \\
\hline 19 & $28.7^{\mathrm{a}}$ & 4.1 & $18.2^{\mathrm{ad}}$ & 4.1 & 24.7 & 3.2 & $29.8^{\mathrm{d}}$ & 3.2 \\
\hline 22 & 19.3 & 2.9 & $22.4^{\mathrm{d}}$ & 2.9 & $14.8^{\mathrm{b}}$ & 2.3 & $30.6^{\mathrm{bd}}$ & 2.3 \\
\hline 24 & 20.2 & 3.1 & $26.9^{\mathrm{d}}$ & 3.1 & $20.6^{\mathrm{b}}$ & 2.4 & $44.3^{\mathrm{bd}}$ & 2.4 \\
\hline 28 & $36.0^{c}$ & 3.7 & 32.8 & 3.7 & $20.8^{\mathrm{bc}}$ & 2.9 & $41.3^{\mathrm{b}}$ & 2.9 \\
\hline 29 & 38.8 & 3.7 & $33.4^{\mathrm{d}}$ & 3.7 & 44.0 & 2.8 & $50.6^{\mathrm{d}}$ & 2.8 \\
\hline
\end{tabular}

Significant p-value for multiple comparison of panel * view interaction

${ }^{\text {a }}$ Repose vs. smile for orthodontist.

${ }^{\mathrm{b}}$ Repose vs. smile for laypeople

${ }^{\mathrm{c}}$ Orthodontist vs. laypeople for repose

${ }^{\mathrm{d}}$ Orthodontist vs. laypeople for smile 
Adjusted multiple comparison of Least square (LS) means of ranking scores for patients with significant sex $*$ view interaction

\begin{tabular}{|c|c|c|c|c|c|c|c|c|}
\hline \multirow[b]{3}{*}{ Patient } & \multicolumn{4}{|c|}{ Male } & \multicolumn{4}{|c|}{ Female } \\
\hline & \multicolumn{2}{|c|}{ REPOSE } & \multicolumn{2}{|l|}{ SMILE } & \multicolumn{2}{|c|}{ REPOSE } & \multicolumn{2}{|l|}{ SMILE } \\
\hline & $\begin{array}{l}\text { LS } \\
\text { MEAN }\end{array}$ & $\begin{array}{l}\text { Std } \\
\text { Err }\end{array}$ & $\begin{array}{l}\text { LS } \\
\text { MEAN }\end{array}$ & $\begin{array}{l}\text { Std } \\
\text { Err }\end{array}$ & $\begin{array}{l}\text { LS } \\
\text { MEAN }\end{array}$ & $\begin{array}{l}\text { Std } \\
\text { Err }\end{array}$ & $\begin{array}{l}\text { LS } \\
\text { MEAN }\end{array}$ & Std Err \\
\hline 16 & 38.0 & 3.4 & 38.9 & 3.4 & $47.2^{\mathrm{b}}$ & 3.4 & $34.0^{\mathrm{b}}$ & 3.4 \\
\hline 18 & 25.1 & 2.8 & 26.9 & 2.8 & $28.7^{\mathrm{b}}$ & 2.8 & $19.8^{\mathrm{b}}$ & 2.8 \\
\hline 23 & 35.4 & 3.3 & $30.7^{\mathrm{d}}$ & 3.3 & $28.5^{\mathrm{b}}$ & 3.3 & $42.9^{\text {bd }}$ & 3.3 \\
\hline 30 & $32.0^{\mathrm{a}}$ & 3.0 & $43.5^{\mathrm{ad}}$ & 3.0 & $27.9^{\mathrm{b}}$ & 3.0 & $52.5^{\text {bd }}$ & 3.0 \\
\hline
\end{tabular}

Significant $\mathrm{p}$-value for multiple comparison of sex* view interaction

${ }^{\text {a }}$ Repose vs. smile for orthodontist.

${ }^{\mathrm{b}}$ Repose vs. smile for laypeople

${ }^{\mathrm{d}}$ Orthodontist vs. laypeople for smile 
Means of ranking scores for GV position by rater

\begin{tabular}{|c|c|c|c|c|c|c|c|}
\hline \multirow[b]{3}{*}{ Rater } & \multicolumn{6}{|c|}{ GV Position } & \multirow[b]{3}{*}{ p-value* } \\
\hline & \multicolumn{2}{|c|}{ Black } & \multicolumn{2}{|c|}{ Green } & \multicolumn{2}{|c|}{ Red } & \\
\hline & MEAN & SD & MEAN & SD & MEAN & SD & \\
\hline 1 & 33.72 & 16.16 & 35.75 & 20.69 & 18.38 & 17.60 & 0.10 \\
\hline 2 & 30.78 & 18.53 & 46.00 & 11.40 & 28.50 & 17.47 & 0.25 \\
\hline 3 & $25.44^{\mathrm{a}}$ & 16.58 & $54.75^{\mathrm{ab}}$ & 2.87 & $22.88^{\mathrm{b}}$ & 14.67 & 0.004 \\
\hline 4 & 26.00 & 12.45 & 38.00 & 19.25 & 32.38 & 19.89 & 0.32 \\
\hline 5 & $20.83^{\mathrm{a}}$ & 16.29 & $45.50^{\mathrm{a}}$ & 14.11 & 35.25 & 15.13 & 0.01 \\
\hline 6 & 31.78 & 16.62 & 39.75 & 13.23 & 20.88 & 20.65 & 0.18 \\
\hline 7 & 23.67 & 14.00 & 43.50 & 18.84 & 25.50 & 20.20 & 0.11 \\
\hline 8 & 23.83 & 16.81 & 41.00 & 17.57 & 32.75 & 18.71 & 0.17 \\
\hline 9 & $18.28^{\mathrm{ac}}$ & 11.13 & $51.25^{\mathrm{a}}$ & 8.77 & $38.38^{\mathrm{c}}$ & 17.88 & 0.0001 \\
\hline 10 & 20.94 & 13.09 & 27.75 & 22.29 & 26.38 & 18.07 & 0.60 \\
\hline 11 & 43.61 & 13.05 & 47.25 & 12.50 & 29.75 & 21.60 & 0.09 \\
\hline 12 & $36.72^{\mathrm{c}}$ & 16.52 & 32.50 & 6.35 & $16.13^{\mathrm{c}}$ & 15.25 & 0.01 \\
\hline 13 & 35.39 & 19.40 & $48.50^{\mathrm{b}}$ & 8.96 & $21.25^{\mathrm{b}}$ & 15.77 & 0.05 \\
\hline 14 & 37.17 & 18.79 & 45.75 & 13.35 & 22.75 & 17.09 & 0.08 \\
\hline 15 & 33.28 & 16.09 & 32.00 & 16.57 & 23.50 & 18.77 & 0.40 \\
\hline 16 & $43.72^{\mathrm{c}}$ & 14.30 & 42.00 & 8.29 & $25.13^{\mathrm{c}}$ & 15.64 & 0.01 \\
\hline 17 & $35.67^{\mathrm{c}}$ & 18.35 & 25.75 & 15.26 & $12.13^{c}$ & 10.16 & 0.008 \\
\hline 18 & 33.72 & 15.86 & 35.00 & 12.83 & 24.50 & 19.91 & 0.40 \\
\hline 19 & 28.39 & 18.51 & 38.75 & 20.85 & 28.25 & 17.24 & 0.58 \\
\hline 20 & $34.61^{\mathrm{c}}$ & 18.66 & $39.75^{\mathrm{b}}$ & 24.57 & $10.88^{\mathrm{bc}}$ & 7.00 & 0.007 \\
\hline 21 & $38.78^{\mathrm{c}}$ & 15.53 & 29.75 & 6.18 & $17.00^{\mathrm{c}}$ & 15.53 & 0.007 \\
\hline 22 & $37.78^{\mathrm{c}}$ & 15.49 & 35.25 & 19.16 & $15.25^{\mathrm{c}}$ & 16.02 & 0.009 \\
\hline 23 & 37.67 & 16.07 & 36.25 & 10.34 & 23.25 & 16.62 & 0.11 \\
\hline 24 & 30.78 & 19.17 & 33.00 & 17.20 & 22.50 & 15.28 & 0.50 \\
\hline 25 & $43.28^{\mathrm{c}}$ & 12.94 & $45.50^{\mathrm{b}}$ & 7.55 & $23.50^{\mathrm{bc}}$ & 18.71 & 0.007 \\
\hline 26 & $44.56^{\mathrm{c}}$ & 11.21 & $45.25^{\mathrm{b}}$ & 11.59 & $22.13^{\mathrm{bc}}$ & 18.42 & 0.002 \\
\hline 27 & 41.89 & 14.75 & 35.75 & 11.79 & 35.88 & 18.15 & 0.58 \\
\hline 28 & 41.06 & 17.57 & 46.00 & 8.64 & 26.00 & 18.85 & 0.09 \\
\hline 29 & 30.00 & 20.19 & 38.50 & 9.88 & 17.38 & 14.70 & 0.13 \\
\hline 30 & 40.94 & 13.64 & 30.25 & 7.89 & 27.63 & 20.58 & 0.11 \\
\hline 31 & 27.83 & 15.52 & 42.75 & 10.40 & 21.25 & 12.34 & 0.07 \\
\hline 32 & 30.17 & 12.99 & 42.50 & 15.07 & 35.13 & 19.27 & 0.32 \\
\hline
\end{tabular}

$*$ p-value from ANOVA test

Significant p-value for multiple comparison of GV position

${ }^{\text {a }}$ Black vs. Green position.

${ }^{\mathrm{b}}$ Green vs. Red position

${ }^{c}$ Blackt vs. Red position 
Mixed model analysis of ranking scores for all patients. Test of main effects for rater (panel), panel, sex, view, panel* view, sex *view interaction

\begin{tabular}{|c|c|c|c|c|}
\hline source & NDF & DDF & F & Pr $>$ F \\
\hline Fixed Effect & & & & \\
\hline View & 1 & 1856 & 10.45 & 0.0012 \\
\hline Panel & 1 & 29 & 1.75 & 0.1963 \\
\hline Sex & 1 & 29 & 1.43 & 0.2410 \\
\hline Panel*View & 1 & 1856 & 43.50 & $<0.0001$ \\
\hline Sex*View & 1 & 1856 & 0.14 & 0.7072 \\
\hline & & & $Z$ & Pr $>\mathrm{Z}$ \\
\hline Random Effect & & & & \\
\hline Rater(Panel) & & & -30.25 & $<0.0001$ \\
\hline Patient & & & 3.60 & 0.0003 \\
\hline
\end{tabular}

Table 9 Multiple comparison for Panel*View interaction

\begin{tabular}{|l|l|l|l|l|l|l|l|}
\hline \multicolumn{4}{|l|}{ Orthodontist } & \multicolumn{3}{l|}{ Lay-people } \\
\hline Repose & \multicolumn{3}{|l|}{ Smile } & Repose & \multicolumn{2}{l|}{ Smile } \\
\hline LS & Std & LS & Std & LS & Std & LS & Std \\
MEAN & Err & MEAN & Err & MEAN & Err & MEAN & Err \\
\hline $31.2^{\text {ac }}$ & 1.6 & $28.8^{\text {ad }}$ & 1.6 & $26.4^{\text {bc }}$ & 1.5 & $33.5^{\text {bd }}$ & 1.5 \\
\hline
\end{tabular}

Significant p-value for multiple comparison of sex* view interaction

${ }^{\text {a }}$ Repose vs. smile for orthodontist.

${ }^{\mathrm{b}}$ Repose vs. smile for laypeople

${ }^{\mathrm{c}}$ Orthodontist vs. lay-people for repose

${ }^{\mathrm{d}}$ Orthodontist vs. laypeople for smile 
Mixed model analysis of ranking scores for all patients. Test of main effects for rater (panel), patient, panel, sex, GVP , panel* GVP, sex *GVP interaction

\begin{tabular}{|c|c|c|c|c|}
\hline source & NDF & DDF & $\mathrm{F}$ & $\operatorname{Pr}>\mathrm{F}$ \\
\hline \multicolumn{5}{|l|}{ Fixed Effect } \\
\hline GVP & 2 & 27.2 & 3.22 & 0.0555 \\
\hline Panel & 1 & 40.7 & 0.07 & 0.7862 \\
\hline Sex & 1 & 40.7 & 0.17 & 0.6828 \\
\hline Panel*GVP & 2 & 895 & 42.98 & $<0.0001$ \\
\hline \multirow[t]{2}{*}{ Sex*GVP } & 2 & 895 & 1.56 & 0.2116 \\
\hline & & & $\mathrm{Z}$ & Pr $>Z$ \\
\hline \multicolumn{5}{|l|}{ Random Effect } \\
\hline Rater(Panel) & & & 2.18 & 0.0291 \\
\hline Patient & & & 3.46 & 0.0005 \\
\hline
\end{tabular}

$\mathrm{GVP}=\mathrm{GV}$ position

Multiple comparison for Panel* ${ }^{*} \mathrm{GV}$ position interaction

\begin{tabular}{|l|l|l|l|l|l|l|l|l|l|l|l|}
\hline \multicolumn{9}{|l|}{ Orthodontist } & \multicolumn{4}{l|}{ Lay-people } \\
\hline Black & \multicolumn{3}{l|}{ Green } & \multicolumn{2}{l|}{ Red } & \multicolumn{1}{l|}{ Black } & Red & \\
\hline LS & Std & LS & Std & LS & Std & LS & Std & LS & Std & LS & Std \\
MEAN & Err & MEAN & Err & MEAN & Err & MEAN & Err & MEAN & Err & MEAN & Err \\
\hline $26.1^{\text {af }}$ & 2.6 & $42.4^{\text {ab }}$ & 5.2 & $28.1^{\text {be }}$ & 3.7 & $37.5^{\text {df }}$ & 2.4 & $38.1^{\text {c }}$ & 5.0 & $22.2^{\text {cde }}$ & 3.6 \\
\hline
\end{tabular}

Significant $\mathrm{p}$-value for multiple comparison of panel*GVP

${ }^{a}$ Black vs. Green GV position for orthodontist.

${ }^{\mathrm{b}}$ Red vs. Green GV position for orthodontist.

${ }^{\mathrm{c}}$ Red vs. Green GV position for lay-people.

${ }^{\mathrm{d}}$ Red vs. Black GV position for lay-people.

${ }^{\mathrm{e}}$ Orthodontist vs Lay-people for Red GV position

${ }^{\mathrm{f}}$ Orthodontist vs Lay-people for Black GV position 
Means of rating scores for smile by patient

\begin{tabular}{|l|l|l|r|r|}
\hline Patient & GV & Position & MEAN & SD \\
\hline 1 & 1 & R & 38.53 & 17.58 \\
\hline 2 & -7 & B & 59.09 & 22.58 \\
\hline 3 & -5 & B & 56.56 & 17.93 \\
\hline 4 & -11 & B & 48.25 & 15.45 \\
\hline 5 & -8 & B & 60.41 & 16.55 \\
\hline 6 & -1 & B & 40.97 & 15.79 \\
\hline 7 & -13 & B & 58.41 & 18.56 \\
\hline 8 & -9 & B & 46.69 & 18.28 \\
\hline 9 & -7 & B & 56.66 & 15.60 \\
\hline 10 & 6 & R & 26.66 & 18.99 \\
\hline 11 & 4 & R & 22.19 & 11.98 \\
\hline 12 & -3 & B & 40.53 & 19.70 \\
\hline 13 & -9 & B & 32.97 & 18.36 \\
\hline 14 & 5 & R & 46.97 & 16.23 \\
\hline 15 & -6 & B & 67.53 & 14.22 \\
\hline 16 & 2 & R & 54.22 & 13.86 \\
\hline 17 & 0 & G & 52.03 & 18.41 \\
\hline 18 & -4 & B & 43.38 & 12.99 \\
\hline 19 & -6 & B & 43.63 & 15.69 \\
\hline 20 & 0 & G & 60.31 & 18.83 \\
\hline 21 & 3 & R & 44.88 & 16.77 \\
\hline 22 & -2 & B & 45.94 & 13.40 \\
\hline 23 & -11 & B & 57.56 & 14.73 \\
\hline 24 & -3 & B & 56.84 & 17.24 \\
\hline 25 & -2 & B & 64.66 & 14.92 \\
\hline 26 & 1 & R & 52.59 & 19.98 \\
\hline 27 & 8 & R & 55.97 & 15.18 \\
\hline 28 & 0 & G & 56.91 & 16.18 \\
\hline 29 & -5 & B & 64.34 & 14.97 \\
\hline 30 & 0 & G & 66.72 & 14.15 \\
\hline & & & & \\
\hline
\end{tabular}


Means of rating scores (smile) of panel by patient

\begin{tabular}{|c|c|c|c|c|c|c|c|}
\hline \multirow[t]{2}{*}{ Patient } & \multirow[t]{2}{*}{$\mathrm{GV}$} & \multirow[t]{2}{*}{ position } & \multicolumn{2}{|c|}{ Orthodontist } & \multicolumn{2}{|c|}{ Lay-people } & \multirow{2}{*}{$\begin{array}{l}\mathrm{p}- \\
\text { value* }\end{array}$} \\
\hline & & & MEAN & SD & MEAN & SD & \\
\hline 1 & 1 & $\mathrm{R}$ & 47.83 & 13.97 & 32.95 & 17.42 & 0.02 \\
\hline 2 & -7 & B & 51.50 & 22.54 & 63.65 & 21.90 & 0.14 \\
\hline 3 & -5 & B & 52.00 & 19.31 & 59.30 & 16.96 & 0.27 \\
\hline 4 & -11 & $\mathrm{~B}$ & 39.50 & 11.57 & 53.50 & 15.31 & 0.01 \\
\hline 5 & -8 & B & 48.08 & 19.69 & 67.80 & 8.32 & 0.01 \\
\hline 6 & -1 & $\mathrm{~B}$ & 31.17 & 15.52 & 46.85 & 13.04 & 0.005 \\
\hline 7 & -13 & $\mathrm{~B}$ & 45.42 & 21.56 & 66.20 & 11.07 & 0.001 \\
\hline 8 & -9 & B & 41.67 & 20.79 & 49.70 & 16.41 & 0.23 \\
\hline 9 & -7 & B & 51.08 & 16.87 & 60.00 & 14.17 & 0.12 \\
\hline 10 & 6 & $\mathrm{R}$ & 34.67 & 26.22 & 21.85 & 11.19 & 0.13 \\
\hline 11 & 4 & $\mathrm{R}$ & 25.50 & 14.57 & 20.20 & 10.00 & 0.23 \\
\hline 12 & -3 & B & 43.00 & 19.36 & 39.05 & 20.24 & 0.59 \\
\hline 13 & -9 & B & 33.25 & 15.68 & 32.80 & 20.18 & 0.95 \\
\hline 14 & 5 & $\mathrm{R}$ & 46.83 & 20.70 & 47.05 & 13.48 & 0.97 \\
\hline 15 & -6 & B & 71.75 & 17.76 & 65.00 & 11.37 & 0.20 \\
\hline 16 & 2 & $\mathrm{R}$ & 59.17 & 16.06 & 51.25 & 11.81 & 0.12 \\
\hline 17 & 0 & $\mathrm{G}$ & 53.25 & 20.19 & 51.30 & 17.76 & 0.78 \\
\hline 18 & -4 & $\mathrm{~B}$ & 45.58 & 14.13 & 42.05 & 12.45 & 0.47 \\
\hline 19 & -6 & $\mathrm{~B}$ & 36.42 & 18.87 & 47.95 & 11.96 & 0.04 \\
\hline 20 & 0 & $\mathrm{G}$ & 76.42 & 16.97 & 50.65 & 12.23 & $<0.0001$ \\
\hline 21 & 3 & $\mathrm{R}$ & 51.67 & 21.42 & 40.80 & 12.10 & 0.08 \\
\hline 22 & -2 & B & 41.50 & 15.10 & 48.60 & 11.88 & 0.18 \\
\hline 23 & -11 & B & 51.17 & 14.10 & 61.40 & 14.06 & 0.06 \\
\hline 24 & -3 & B & 47.67 & 18.90 & 62.35 & 13.89 & 0.02 \\
\hline 25 & -2 & $\mathrm{~B}$ & 64.00 & 18.22 & 65.05 & 13.05 & 0.85 \\
\hline 26 & 1 & $\mathrm{R}$ & 56.33 & 24.47 & 50.35 & 17.04 & 0.42 \\
\hline 27 & 8 & $\mathrm{R}$ & 58.67 & 20.33 & 54.35 & 11.37 & 0.45 \\
\hline 28 & 0 & $\mathrm{G}$ & 55.08 & 23.95 & 58.00 & 9.58 & 0.69 \\
\hline 29 & -5 & B & 57.17 & 17.11 & 68.65 & 11.99 & 0.03 \\
\hline 30 & 0 & $\mathrm{G}$ & 73.83 & 15.18 & 62.45 & 11.92 & 0.02 \\
\hline
\end{tabular}

*P-value from two sample t-test analysis 
Means of rating scores (smile) of sex by patient

\begin{tabular}{|c|c|c|c|c|c|c|c|}
\hline \multirow[t]{2}{*}{ Patient } & \multirow[t]{2}{*}{ GV } & \multirow[t]{2}{*}{ position } & \multicolumn{2}{|l|}{ Male } & \multicolumn{2}{|l|}{ Female } & \multirow[b]{2}{*}{$\begin{array}{l}\mathrm{P}- \\
\text { value* }\end{array}$} \\
\hline & & & MEAN & SD & MEAN & SD & \\
\hline 1 & 1 & $\mathrm{R}$ & 34.00 & 16.74 & 43.06 & 17.73 & 0.15 \\
\hline 2 & -7 & B & 61.50 & 25.24 & 56.69 & 20.11 & 0.56 \\
\hline 3 & -5 & B & 58.00 & 18.81 & 55.13 & 17.49 & 0.66 \\
\hline 4 & -11 & $\mathrm{~B}$ & 46.19 & 13.41 & 50.31 & 17.44 & 0.46 \\
\hline 5 & -8 & B & 59.13 & 15.93 & 61.69 & 17.58 & 0.67 \\
\hline 6 & -1 & B & 40.50 & 17.24 & 41.44 & 14.74 & 0.87 \\
\hline 7 & -13 & B & 55.50 & 19.90 & 61.31 & 17.26 & 0.38 \\
\hline 8 & -9 & B & 44.44 & 22.79 & 48.94 & 12.66 & 0.50 \\
\hline 9 & -7 & B & 49.75 & 15.19 & 63.56 & 13.06 & 0.01 \\
\hline 10 & 6 & $\mathrm{R}$ & 23.63 & 15.41 & 29.69 & 22.10 & 0.38 \\
\hline 11 & 4 & $\mathrm{R}$ & 23.06 & 10.31 & 21.31 & 13.73 & 0.69 \\
\hline 12 & -3 & B & 38.69 & 19.82 & 42.38 & 20.04 & 0.60 \\
\hline 13 & -9 & $\mathrm{~B}$ & 33.50 & 21.77 & 32.44 & 14.90 & 0.87 \\
\hline 14 & 5 & $\mathrm{R}$ & 44.63 & 17.62 & 49.31 & 14.90 & 0.42 \\
\hline 15 & -6 & B & 62.94 & 11.59 & 72.13 & 15.44 & 0.07 \\
\hline 16 & 2 & $\mathrm{R}$ & 54.63 & 8.78 & 53.81 & 17.88 & 0.87 \\
\hline 17 & 0 & $\mathrm{G}$ & 49.38 & 17.82 & 54.69 & 19.18 & 0.42 \\
\hline 18 & -4 & B & 45.00 & 13.69 & 41.75 & 12.48 & 0.49 \\
\hline 19 & -6 & B & 43.63 & 15.75 & 43.63 & 16.16 & 1.00 \\
\hline 20 & 0 & $\mathrm{G}$ & 59.81 & 19.81 & 60.81 & 18.43 & 0.88 \\
\hline 21 & 3 & $\mathrm{R}$ & 40.50 & 16.76 & 49.25 & 16.10 & 0.14 \\
\hline 22 & -2 & B & 46.38 & 11.21 & 45.50 & 15.66 & 0.86 \\
\hline 23 & -11 & B & 49.31 & 13.03 & 65.81 & 11.55 & 0.0007 \\
\hline 24 & -3 & B & 49.88 & 18.12 & 63.81 & 13.50 & 0.02 \\
\hline 25 & -2 & B & 61.25 & 12.59 & 68.06 & 16.63 & 0.20 \\
\hline 26 & 1 & $\mathrm{R}$ & 50.31 & 19.85 & 54.88 & 20.49 & 0.53 \\
\hline 27 & 8 & $\mathrm{R}$ & 57.25 & 11.05 & 54.69 & 18.72 & 0.64 \\
\hline 28 & 0 & $\mathrm{G}$ & 50.56 & 15.47 & 63.25 & 14.69 & 0.02 \\
\hline 29 & -5 & B & 63.56 & 18.44 & 65.13 & 11.03 & 0.77 \\
\hline 30 & 0 & $\mathrm{G}$ & 60.38 & 13.28 & 73.06 & 12.32 & 0.01 \\
\hline
\end{tabular}

*P-value from two sample t-test analysis 
Contingency table of GV position by Opinion

\begin{tabular}{|l|l|l|l|l|}
\hline $\begin{array}{l}\text { GV } \\
\text { position }\end{array}$ & $\begin{array}{l}\text { Stay } \\
(\%)\end{array}$ & $\begin{array}{l}\text { Forward } \\
(\%)\end{array}$ & $\begin{array}{l}\text { Backward } \\
(\%)\end{array}$ & $\begin{array}{l}\text { p- } \\
\text { value* }\end{array}$ \\
\hline B & 49.3 & 44.4 & 6.3 & $<0.0001$ \\
\hline G & 68.0 & 26.6 & 5.5 & \\
\hline R & 43.1 & 15.3 & 41.6 & \\
\hline
\end{tabular}

$* \mathrm{p}$-value for Chi-square analysis

Contingency table of GV position by Opinion by Panel

\begin{tabular}{|l|l|l|l|l|l|l|l|l|}
\hline \multirow{2}{*}{$\begin{array}{l}\text { GV } \\
\text { Position }\end{array}$} & \multicolumn{3}{|l|}{ Orthodontist } & P-value* & \multicolumn{2}{|l|}{ Lay-people } & P- \\
\cline { 2 - 3 } & Stay & Forward & Backward & & Stay & Forward & Backward & value* \\
\hline B & 32.9 & 65.7 & 1.4 & $<0.0001$ & 59.2 & 31.7 & 9.2 & $<0.0001$ \\
\hline G & 79.2 & 18.8 & 2.1 & & 61.3 & 31.3 & 7.5 & \\
\hline R & 53.1 & 5.2 & 41.7 & & 37.1 & 21.4 & 41.5 & \\
\hline
\end{tabular}

*p-value from The Cochran-Mantel-Haenszel statistic

Contingency table of GV position by Opinion by Panel

\begin{tabular}{|c|c|c|c|c|c|c|c|c|c|c|c|c|}
\hline & \multicolumn{3}{|c|}{$\mathrm{B}$} & \multirow[b]{2}{*}{$\begin{array}{l}\text { P- } \\
\text { value* }\end{array}$} & \multicolumn{3}{|c|}{$\mathrm{G}$} & \multirow[b]{2}{*}{$\mathrm{P}$} & \multicolumn{3}{|c|}{$\mathrm{R}$} & \multirow[b]{2}{*}{$\begin{array}{l}\text { P- } \\
\text { value* }\end{array}$} \\
\hline Panel & $S$ & $\mathrm{~F}$ & $\mathrm{~B}$ & & $S$ & $\mathrm{~F}$ & $\mathrm{~B}$ & & $\mathrm{~S}$ & $F$ & B & \\
\hline Orthodontist & 32.9 & 65.8 & 1.4 & \multirow[t]{2}{*}{$<0.0001$} & 79.2 & 18.8 & 2.1 & \multirow[t]{2}{*}{$<0.09$} & 53.1 & 5.2 & 41.7 & \multirow[t]{2}{*}{0.001} \\
\hline Lay-people & 59.2 & 31.7 & 9.2 & & 61.3 & 31.3 & 7.5 & & 37.1 & 21.4 & 41.5 & \\
\hline
\end{tabular}

*p-value from The Cochran-Mantel-Haenszel statistic 
PART I: Instructions: You will be shown 30 smiling and 30 nonsmiling profile photographs for 15 seconds each and asked to judge the attractiveness of the profiles, particularly the area of the mouth from "least attractive" (0) to "most attractive" (100). You will mark an "X" on the line below to represent where the subject falls on the scale of least to most attractive.

$\# 1$

"Least Attractive"

"Most Attractive"

\#2

"Least Attractive"

"Most Attractive"

\#3

"Least Attractive"

"Most Attractive"

\#4

"Least Attractive"

"Most Attractive"

PART II: Instructions: You will be shown $\mathbf{3 0}$ smiling profile photographs in random order for 15 seconds each and asked whether you would prefer the upper front teeth to stay in the same position, move forward, or move backward. Please circle the corresponding option for each photograph.

\#1 Would you like the position of the upper front teeth to:
Stay the same
Move forward
Move backward

\#2 Would you like the position of the upper front teeth to:

Stay the same Move forward Move backward 